\title{
QCM-D study of time-resolved cell adhesion and detachment: Effect of surface free energy on eukaryotes and prokaryotes
}

\author{
Derick Yongabi ${ }^{a^{*},}$ Mehran Khorshid ${ }^{a}$, Alessia Gennaro ${ }^{a}$, Stijn Jooken ${ }^{a}$, Sam Duwé ${ }^{b}$, \\ Olivier Deschaume ${ }^{\mathrm{a}}$, Patricia Losada-Pérez ${ }^{\mathrm{c}}$, Peter Dedecker ${ }^{\mathrm{b}}$, Carmen Bartic ${ }^{\mathrm{a}}$, \\ Michael Wübbenhorst ${ }^{a}$, Patrick Wagner ${ }^{a}$
}

${ }^{a}$ KU Leuven, Department of Physics and Astronomy, Laboratory for Soft Matter and Biophysics, Celestijnenlaan 200 D, B-3001 Leuven, Belgium

${ }^{\mathrm{b}} \mathrm{KU}$ Leuven, Department of Chemistry, Laboratory for Nanobiology, Celestinenlaan $200 \mathrm{G}$, B-3001, Leuven, Belgium

${ }^{\mathrm{c}}$ Université Libre de Bruxelles (ULB), Experimental Soft Matter and Thermal Physics Group, Campus La Plaine, CP223, Boulevard du Triomphe, 1050 Brussels, Belgium.

\section{* Corresponding author}

Drs. Derick Yongabi

KU Leuven

Laboratory for Soft-Matter and Biophysics

Celestijnenlaan 200 D

B-3001 Leuven, Belgium

Tel : +3216376874

E-mail: derick.yongabi@kuleuven.be

\begin{abstract}
Cell-material interactions are crucial for many biomedical applications, including medical implants, tissue engineering and biosensors. For implants, while the adhesion of eukaryotic host cells is desirable, bacterial adhesion often leads to infections. Surface free energy (SFE) is an important parameter that controls short- and long-term eukaryotic and prokaryotic cell adhesion. Understanding its effect at a fundamental level is essential for designing materials that minimize bacterial adhesion. Most cell adhesion studies for implants have focused on correlating surface wettability with mammalian cell adhesion and are restricted to short-term time scales. In this work, we used quartz crystal microbalance with dissipation monitoring (QCM-D) and electrical impedance analysis to characterise the adhesion and detachment of S. cerevisiae and E. coli, serving as model eukaryotic and prokaryotic cells, within extended time scales. Measurements were performed on surfaces displaying different
\end{abstract}


surface energies $\left(\mathrm{Au}, \mathrm{SiO}_{2}\right.$ and silanized $\left.\mathrm{SiO}_{2}\right)$. Our results demonstrate that tuning the surface free energy of materials is a useful strategy for selectively promoting eukaryotic cell adhesion and preventing bacterial adhesion. Specifically, we show that under flow and steady-state conditions, within time scales up to $\approx 10$ hours, a high SFE, especially its polar component enhances $S$. cerevisiae adhesion and hinders E. coli adhesion. In the long term, however, both cells tend to detach, but less detachment occurs on surfaces with a high dispersive SFE contribution. The conclusions on $S$. cerevisiae are also valid for a second eukaryotic cell type, being the human embryonic kidney (HEK) cells on which we performed the same analysis for comparison. Furthermore, each cell adhesion phase is associated with unique cytoskeletal viscoelastic states, which are cell-type-specific and surface free energy-dependent and provide insights into the underlying adhesion mechanisms.

Keywords: Cell adhesion, cell detachment, surface free energy, viscoelasticity, QCM-D, impedance spectroscopy.

\section{Introduction}

Cell adhesion and detachment are crucial to many aspects of cell function and biological processes as well as biomedical and bio-engineering applications. Basic cellular processes, such as cellular communication, growth, migration, and differentiation are strongly controlled by cell adhesion and detachment ${ }^{1-3}$. As a result, abnormalities in the adhesion and detachment behavior of cells accompany many pathological conditions. For example, the organ preferences for circulating tumour-cell invasion have been linked to changes in the adhesion receptors and the cell mechanical properties ${ }^{4,5}$. Also, cell adhesion is a key parameter in the overall cellmaterial interactions, which are critical for many applications, such as tissue engineering ${ }^{6-8}$, biosensors $^{9}$, cell-based therapy ${ }^{10,11}$ and implant materials ${ }^{12,13}$. 
Despite recent advances in cell adhesion studies, many aspects of adhesion still require deeper exploration: For instance, the fate of medical implants depends critically on whether human or microbial cells adhere to the implanted material. Adhesion of the former is desired, while adhesion of the latter leads to biofilm formation and infections that may necessitate highcost interventions ${ }^{14,15}$. Therefore, designing implant materials that promote eukaryotic cell adhesion, while inhibiting the adhesion of bacteria is important ${ }^{13}$. However, current studies on cell-material interactions for implants mostly focus on mammalian cells ${ }^{16,5}$. Therefore, there is also a high need to understand the dynamics of microbial adhesion, both in the short and longterm. Also relevant is cell adhesion under shear flow ${ }^{17,18}$. Thus, non-invasive and real-time studies are needed to gain insight into the time-resolved adhesion kinetics of freely flowing cells.

The adhesion properties of cell populations have been studied using techniques such as centrifuge and shear-force assays ${ }^{19}$. At the single-cell level, techniques including atomic force microscopy ${ }^{20}$, magnetic bead twisting cytometry ${ }^{21}$, and optical trapping ${ }^{22}$ have been employed to study cell adhesion properties. These techniques, whether they examine cell populations or single cells, depend on end point detection and provide no information on the real-time adhesion and detachment behavior 5 . In addition, these techniques are invasive because they apply mechanical forces on the cells and/or introduce foreign materials such as fluorescent labels. Such invasiveness can result in undesirable effects, such as denaturation, lysis, and rupture, which affect the intrinsic cell adhesion behavior ${ }^{16,23}$. Recently, a novel method based on thermal-resistance analysis was successfully used to monitor cell adhesion in real-time ${ }^{24-26}$. Although thermal methods can monitor the surface coverage of a chip resulting from cell attachment, they are still not sensitive to cytoskeletal changes that accompany cell adhesion. This brings us to the method of choice for this application, being the quartz crystal microbalance with dissipation monitoring (QCM-D). 
QCM-D is a highly sensitive, non-invasive and label-free platform that can monitor the adhesion of biological entities in real-time, including cells, lipids and proteins ${ }^{27-29}$. A QCM-D simultaneously measures changes in the frequency $(\Delta f)$, and energy dissipation $(\Delta D)$ of an ATcut quartz crystal, corresponding to changes in the mass loading and viscoelastic properties of the solid-liquid interface due to adsorbing cells ${ }^{30,29}$. This allows to evaluate different aspects of cell adhesion, including kinetics of cell attachment, spreading, growth and cytoskeletal changes $^{31-34}$.

Cell adhesion often exhibits complex time-dependent patterns that depend on properties of the substrate surface, the liquid medium as well as the cellular electrical and mechanical properties. Amongst these parameters, surface free energy (SFE), which depends on the substrate surface chemistry is decisive for modulating cell adhesion ${ }^{35,36}$. SFE can be regarded as the surface tension of a solid and describes the excess energy that surface atoms possess due to unsaturated bonds compared with bulk atoms for which all bonds are fully saturated. The magnitude of this energy is determined by the type and number of intermolecular forces, which can be considered as either dispersive (van der Waals forces) or polar (hydrogen bonding and dipole-dipole forces $)^{37}$. Previous work on the link between surface chemistry and cell adhesion focused on wettability analysis, which is not a good predictor of cell adhesion in all situations ${ }^{38}$, while few studies, e.g., Nakamura et al., ${ }^{36}$ mostly involving short term mammalian cell adhesion focus on the effect of SFE.

Therefore, many aspects of the global adhesion and detachment dynamics of eukaryotic and prokaryotic cells remain unclear ${ }^{5}$, which brings us to three key questions: i) What is the nature of the material-cell interactions involved in cell adhesion under flow, and how does this compare between eukaryotic and prokaryotic cells? ii) Does steady-state cell adhesion involve a non-invasive detachment phase? iii) What is the role of SFE on cell adhesion and detachment, 
and what is the relation between SFE and cell viscoelasticity in the various phases of cell adhesion?

In this study, through the choice of three substrates with different surface chemistries $\left(\mathrm{Au}, \mathrm{SiO}_{2}\right.$, and silanized $\mathrm{SiO}_{2}$ ), we aim to clarify the effect of SFE on the dynamics of cell adhesion and detachment. Hereby, we also address the internal cellular changes associated with different adhesion phases under flow and non-flow conditions. S. cerevisiae and E. coli were used as models for eukaryotic and prokaryotic cells, respectively. QCM-D and impedance analysis was used as non-invasive techniques for measurements. We focused on the timedependent frequency and dissipation plots to unveil the cell adhesion kinetics under flow and the dynamics of steady-state adhesion and detachment. Dissipation versus frequency (df) analysis was employed to identify the viscoelastic states associated with cell adhesion and detachment. All measurements were performed in pure $1 \times \mathrm{PBS}$ (phosphate-buffered saline) solution to eliminate the effect of complex media and acquire results that reflect only pure cellmaterial interactions. To the best of our knowledge, this is the first time that the SFE dependence of S. cerevisiae adhesion and detachment dynamics are explored in combination with an analysis of viscoelastic changes. In addition, our comparison with SFE dependent $E$. coli adhesion and detachment provides new insights into cell-material interactions that may be useful for developing novel materials with preferential cell-type-specific adhesion properties. Since the adhesion of eukaryotic mammalian cells is essential for medical implants, we also analysed the SFE dependence of Human embryonic kidney cells (HEK T293).

\section{Materials and Methods}

\subsection{QCM-D platform and measurements}

To assess the effect of surface free energy on cell adhesion, the surfaces for QCM-D measurements were chosen that differ markedly in surface chemistry and are relevant for 
implant applications. Two main surfaces, gold, which is largely inert, and silica, which displays a stable oxide layer, were used. The motivation for using gold is two-fold. First, studies correlating surface wettability and cell adhesion have reported a water contact angle of $65 \pm 5$ ${ }^{\circ}$ as the "magic number" for ideal cell adhesion on biomaterials ${ }^{39,40}$. This value corresponds to the water contact angle of clean gold. Secondly, gold is biocompatible and used for implants and prosthetic implant components, such as screws ${ }^{41}$. The choice of $\mathrm{SiO}_{2}$ is based on its use as part of the silicone/silica composite for breast implants ${ }^{42}$ and as a bioactive coating on other metal implant materials such as stainless steel, titanium and tantalum for orthopaedic implants ${ }^{43,44}$. Also, we employed silanized silica surfaces, consisting of - $\mathrm{CH}_{3}$-terminated groups to assess the role of the polar and dispersive SFE components on different aspects of cell adhesion. Silanization of the $\mathrm{SiO}_{2}$ surface allows to change the surface chemistry, thus, achieving control over the SFE while minimally affecting the topography.

For QCM-D measurements, we used a Q-sense E4 instrument and AT-cut quartz crystals (14 $\mathrm{mm}$ diameter, $0.3 \mathrm{~mm}$ thickness, $5 \mathrm{MHz}$ resonance frequency), with gold coating and silica coating (50 nm thickness) purchased from Biolin Scientific (Gothenburg, Sweden). The gold- and $\mathrm{SiO}_{2}$-coated crystals, with similar surface roughness $(<1 \mathrm{~nm})$ were cleaned according to the specifications of the manufacturer. Some clean $\mathrm{SiO}_{2}$-coated crystals were silanized using Trimethylchlorosilane (TMCS) (99\% purity) purchased from abcr GmbH (Karlsruhe, Germany). The chips were silanized by evaporating $20 \mu \mathrm{L}$ of TMCS per chip in a closed container for 15 minutes, rinsed in ethanol (99\% purity), and dried with $\mathrm{N}_{2}$ gas. Ethanol was purchased from VWR International S.A.S, (Fontenay-Sous-Bois, France).

During the QCM-D measurements, the frequency shift and energy dissipation were allowed to equilibrate for at least 20 mins at $37{ }^{\circ} \mathrm{C}$ in $1 \times \mathrm{PBS}(\mathrm{pH} 7.4,137 \mathrm{mM} \mathrm{NaCl}, 2.7 \mathrm{mM}$ $\mathrm{KCl}, 8 \mathrm{mM} \mathrm{Na}_{2} \mathrm{HPO}_{4}$, and $2 \mathrm{mM} \mathrm{KH}_{2} \mathrm{PO}_{4}$ ), thus establishing a stable baseline before adding cell suspensions in $1 \times \mathrm{PBS}$ onto the sensor surface in a flow chamber (volume $40 \mu \mathrm{L}$ ) at a flow 
rate of $100 \mu \mathrm{L} / \mathrm{min}$ for $1 \mathrm{~h}$. Afterwards, the cells were allowed to interact with the surface for a period of at least two days (48 hours) under non-flow conditions. Time-dependent changes in the frequency $(\Delta f)$ and energy dissipation $(\Delta D)$ in response to different phases of cell-surface interactions were monitored simultaneously.

\subsection{Cell preparation and cell cultures}

S. cerevisiae cells were prepared by suspending baker's yeast Dr. Oetker (Bielefeld, Germany) in $1 \times \mathrm{PBS}$ at different concentrations $\left(3.3 \times 10^{4}, 6.6 \times 10^{4}\right.$, and $\left.1.6 \times 10^{5} \mathrm{cells} / \mathrm{mL}\right)$. S. cerevisiae is a well-known model for eukaryotic cells and can withstand more extreme physicochemical conditions than other eukaryotic cells, e.g. mammalian cells. Thus, it is ideal for probing eukaryotic cell behavior under different physicochemical conditions ${ }^{45}$.

The JM109(DE3) E. coli strain was used as a model for prokaryotic cells. E. coli is the organism of choice for studying different aspects of prokaryotic cells, including infection processes and biotechnological applications ${ }^{46,47}$. An important asset is that $E$. coli does not form aggregates, which would be a complication when exploring the cell adhesion kinetics under flow $^{48}$. To allow for fluorescence analysis, JM109(DE3) bacteria were transformed with pRSETb-mEmerald ( $\approx 10 \mathrm{ng}$ plasmid in $50 \mu \mathrm{L}$ cells). This vector contains the coding sequence for the enhanced green fluorescent protein (EGFP) variant, mEmerald. pRSETb-mEmerald preparation, bacteria transformation and cultures were carried out as described in reference 25 . Cells were harvested by centrifuging at $8000 \mathrm{rpm}$ for $5 \mathrm{~min}$ at $4{ }^{\circ} \mathrm{C}$ and re-suspended in pure $1 \times$ PBS buffer. Yeast and bacteria cell concentrations were determined by OD600 measurements using an Ocean Optics ${ }^{\mathrm{TM}}$ Red Tide USB650 VIS-NIR Spectrometer.

Human embryonic kidney cells (HEK T293) were cultured in Dulbecco's Modified Eagle's medium (DMEM) supplemented with 10\% (v/v) heat inactivated Fetal Bovine Serum (FBS), $1 \%(\mathrm{v} / \mathrm{v})$ non-essential amino acids and $1 \%(\mathrm{v} / \mathrm{v})$ penicillin-streptomycin. The cells were 
grown in T-75 culture flasks and placed in a Binder incubator (Tuttlingen, Germany) in a $37^{\circ} \mathrm{C}$ atmosphere with $5 \% \mathrm{CO}_{2}$. Cells were split three times a week upon reaching $90 \%$ confluency. Cells were washed with Dulbecco's phosphate buffered saline without calcium and magnesium, and dissociated by addition of $1 \mathrm{ml}$ of trypsin for $2 \mathrm{~min}$ at $37^{\circ} \mathrm{C}$. Cells were then counted using a handheld Millipore Sigma Scepter ${ }^{\mathrm{TM}}$ cytometer equipped with a $60 \mu \mathrm{m}$ sensor (Fisher Scientific, Geel, Belgium) and seeded in a new flask at a density of $10^{5}$ cells $/ \mathrm{cm}^{2}$. Finally, the cells were washed in $1 \times \mathrm{PBS}$.

\subsection{Zeta potential measurements}

The zeta potential of $S$. cerevisiae suspensions in $1 \times \mathrm{PBS}$ was measured using a zeta potential analyser (ZetaPlus, Brookhaven Instrument Corperation, NY, USA) for two cell concentrations $\left(\approx 10^{5}\right.$ and $\approx 10^{6}$ cells $\left./ \mathrm{mL}\right)$ at $37^{\circ} \mathrm{C}$. Each measurement consisted of five runs from which the system computed the mean zeta potential.

\subsection{Contact angle and surface free energy measurements}

Contact angle and SFE measurements on all surfaces (gold, silica, silanized silica), prepared as described in Section 2.1 were performed with an OCA 25 optical contact angle system (DataPhysics, Filderstadt, Germany). The sessile drop technique was used to measure the contact angle with three test liquids of known surface tension: MilliQ water, ethylene glycol and diiodomethane. A liquid drop of $5 \mu \mathrm{L}$ was used for all measurements and dispensed by an automated syringe. All contact angles were measured at a room temperature of $18{ }^{\circ} \mathrm{C}$. SFE (polar and dispersive) was determined based on the Owens, Wendt, Rabel and Kaelble (OWRK) method ${ }^{37,49}$ described in Section I of the Supporting Information.

Furthermore, we determined the contact angles and SFE values for S. cerevisiae, E. coli and HEK cell monolayers. To achieve this, a cell suspension was pipetted onto a clean Polydimethylsiloxane (PDMS) stamp and the cells were allowed to sediment for at least 30 mins, followed by spin-coating for 60 seconds at $3000 \mathrm{rpm}$ (acceleration, $1000 \mathrm{rpm} / \mathrm{s}$ ) to yield monolayers 
of each cell type $\mathrm{e}^{50}$. As a control, the SFE of PDMS was also determined to ascertain that the SFE of the cell monolayers was not affected by the underlying PDMS layer.

\subsection{Optical and atomic force microscopy}

To visualize the bacteria after long-term adhesion, we used a Leica DM750 M microscope equipped with a HD Digital Camera (Leica MC170 HD) and a LED light source (Leica SFL100, excitation at $470 \mathrm{~nm} \pm 20 \mathrm{~nm}$ ) to measure the fluorescence emitted by the EGFP expressed in E. coli. The fluorescence intensity correlates with the number of live cells and is therefore a measure for cell viability ${ }^{25}$. Brightfield optical images and images obtained using an Agilent 5500 atomic force microscope (AFM) with MSNL-F cantilevers ( $f=110-120 \mathrm{kHz}$, spring constant, $\mathrm{k}=0.6 \mathrm{~N} / \mathrm{m}$, average tip radius $=2-12 \mathrm{~nm}$ ) in intermittent contact mode were used to analyse the structural integrity of the cells. Gwyddion software was used to evaluate the AFM topography images ${ }^{51}$.

\subsection{Yeast cell viability analysis}

To evaluate the viability of the yeast cells after the long-term measurements, a cell suspension was extracted from the surface of a gold chip after a 96-hour adhesion monitoring experiment. The alamarBlue ${ }^{\mathrm{TM}}$ (Resazurin) cell viability reagent was used. Resazurin sodium salt was purchased from Acros Organics, Thermo Fisher Scientific (Geel, Belgium). A $150 \mu \mathrm{M}$ $10 \times$ resazurin solution was prepared in $1 \times \mathrm{PBS}$. For cell viability measurements, $1 \times \mathrm{PBS}$ was supplemented with $15 \mu \mathrm{M}$ of resazurin solution. Cells, in suspension and on the chip, were incubated with the resazurin solution in a six well plate for 3 hours at $37^{\circ} \mathrm{C}$. After 3 hours, 100 $\mu \mathrm{L}$ aliquots were taken and the time-dependent absorbance and fluorescence of resorufin, resulting from the reduction of resazurin by the cells was measured every hour with a Tecan infinite 200PRO microwell plate reader (Tecan Trading AG, Männedorf, Switzerland) at 570 $\mathrm{nm}$ and $590 \mathrm{~nm}$, respectively. 


\subsection{Capacitance and impedance measurements}

Capacitance and impedance measurements were performed using a high-resolution Alpha impedance analyzer (Novocontrol Technologies, Montabaur, Germany). The analyzer provides time- and frequency-dependent information on the capacitance, $C(\omega)$, which is related to the dielectric function $\varepsilon(\omega)$ of the cells through Eq. 1a.

$$
C(\omega)=C_{0} \varepsilon(\omega), \quad Z_{c}(\omega)=\frac{1}{i \omega C(\omega)} \quad \text { Eq. 1a, b }
$$

Where, $C_{0}$ is the capacitance of vacuum, and $\omega$ the angular frequency. The complex impedance in the case of a pure capacitor is given by Eq. 1b. In the lower frequency range, the measurements are more sensitive to the changes at the interface. At such low frequencies, $\left(10^{2}\right.$ $-10^{4} \mathrm{~Hz}$ ), the alternating current (AC) is less able to pass through the cell body due to the high capacitive reactance of the cell membrane (Eq. 1b), which inhibits current flow and restricts charge transfer to intercellular junctions ${ }^{52}$. Therefore, capacitance and impedance monitoring of cell adhesion gives direct information on the temporal overall coverage of the electrode by the cell layer because changes in the area, $A$ of cell membranes and distance, $d$ between the cells and the electrode surface allow to interpret cell attachment, spreading, and detachment $(C$ $=\varepsilon A / d)$. For measurements, a suspension of $1.6 \times 10^{5}$ cells $/ \mathrm{mL}(\approx 500 \mu \mathrm{L}$ volume $)$ was sealed in a liquid parallel plate sample cell (BDS1308, Novocontrol Technologies) at a temperature of $37{ }^{\circ} \mathrm{C}$. Within the $0.1 \mathrm{~Hz}$ to $10^{6} \mathrm{~Hz}$ frequency range (1 V excitation voltage), the impedance was monitored for 48 hours using gold coated parallel plates electrodes to mimic the gold coated QCM chips. 


\section{Results and Discussion}

\subsection{Contact angle, surface free energy and zeta potential}

Table 1 shows that the contact angles and surface free energies of the three surfaces (gold, silica, silanized silica) are considerably different. The highest total SFE of $66.7 \mathrm{mNm}^{-1}$ was measured for silica while the measurement on gold gave $49.4 \mathrm{mNm}^{-1}$. The polar SFE component dominates on silica due to its negatively charged surface, while the dispersive component is higher on gold.

\section{Table 1}

Surface analysis of sensor layers and cells: Contact angle data acquired with three liquids (water, ethylene glycol, and diiodo-methane), and calculated surface free energies for the sensor surfaces, cell layers on PDMS, and pure PDMS. The last column contains the zeta potential of yeast (measured), $\boldsymbol{E}$. coli $^{53}$, and $\boldsymbol{H E K}^{54}$ cells. The errors represent the standard deviations for at least three separate measurements. Figure S2 in the Supporting Information shows representative water contact angles measured on all surfaces with their corresponding SFE plots.

\begin{tabular}{|c|c|c|c|c|c|c|c|}
\hline Sample & $\begin{array}{l}\text { Water } \\
\text { CA }\left(^{\circ}\right)\end{array}$ & $\begin{array}{l}\text { Ethylene } \\
\text { glycol } \\
\text { CA }\left(^{\circ}\right)\end{array}$ & $\begin{array}{l}\text { Diiodo- } \\
\text { methane } \\
\mathrm{CA}\left({ }^{\circ}\right)\end{array}$ & $\begin{array}{c}\text { Surface } \\
\text { energy total } \\
\left(\mathrm{mNm}^{-1}\right)\end{array}$ & $\begin{array}{l}\text { Surface energy } \\
\text { dispersive } \\
\left(\mathrm{mNm}^{-1}\right)\end{array}$ & $\begin{array}{c}\text { Surface } \\
\text { Energy polar } \\
\left(\mathrm{mNm}^{-1}\right)\end{array}$ & $\begin{array}{c}\text { Zeta } \\
\text { potential } \\
(\mathrm{mV})\end{array}$ \\
\hline Gold & $60.6 \pm 0.6$ & $42.1 \pm 1.7$ & $21 \pm 3$ & $49.4 \pm 0.1$ & $40.4 \pm 1.1$ & $9.0 \pm 1$ & \\
\hline Silica & $13 \pm 1$ & $4.6 \pm 0.4$ & $45.4 \pm 0.6$ & $66.7 \pm 1.4$ & $28.6 \pm 1.5$ & $38 \pm 3$ & \\
\hline Silanized & $82 \pm 7$ & $65 \pm 3$ & $66 \pm 1.4$ & $29 \pm 2$ & $22.8 \pm 0.2$ & $7 \pm 2$ & \\
\hline \multicolumn{8}{|l|}{ Silica } \\
\hline Yeast & $42.8 \pm 1.1$ & $32.8 \pm 0.5$ & $75.9 \pm 0.2$ & 51.2 & 17.4 & 33.8 & $-9 \pm 2$ \\
\hline E. coli & $8.5 \pm 0.2$ & $12.9 \pm 0.2$ & $79.4 \pm 1.3$ & 68.0 & 14.8 & 53.2 & $-47.8 \pm 0.7$ \\
\hline HEK & $78.9 \pm 3.5$ & $50.8 \pm 2.9$ & $62.1 \pm 1$ & 32.4 & 25.1 & 7.3 & $-7.4 \pm 3.2$ \\
\hline PDMS & $117.3 \pm 0.2$ & $101.7 \pm 0.5$ & $61.9 \pm 0.2$ & 19.7 & 19.7 & 0.00 & \\
\hline
\end{tabular}

For silanized silica, the total SFE is $29.3 \mathrm{mNm}^{-1}$, indicating that silanization decreases the SFE of native silica by over $50 \%$. The main change in the SFE upon silanization occurs in the polar part, which decreases by $33.3 \mathrm{mNm}^{-1}$, while the dispersive part decreases by only $5.8 \mathrm{mNm}^{-1}$. 
This indicates that silanization decreases the SFE mainly through masking of the surface charge which makes it effective for controlling the polar component of the SFE.

Table 1 also includes the surface free energies of cellular monolayers of E. coli, $S$. cerevisiae and HEK cells, which are $67.9 \mathrm{mNm}^{-1}, 51.2 \mathrm{mNm}^{-1}$ and $33 \mathrm{mNm}^{-1}$ respectively. The difference in the total surface free energies of yeast and HEK compared to E. coli originates mainly from the polar component: $19.3 \mathrm{mNm}^{-1}$ difference between $E$. coli and yeast and 44.9 $\mathrm{mNm}^{-1}$ between $E$. coli and HEK cells. This suggests that the surfaces of $E$. coli contain more polar functional groups and therefore are more charged than $S$. cerevisiae and HEK cell surfaces. Such functional groups include $-\mathrm{COOH},-\mathrm{NH}_{2}$ and $-\mathrm{OH}$, related to lipopolysaccharides, lipoproteins and surface proteins which make the cell surface more negative ${ }^{55}$. Zeta potential reflects cellular surface charge and for S. cerevisiae, we measured -9 $\pm 2 \mathrm{mV}$ in perfect agreement with literature ${ }^{56}$. The literature value for HEK is $-7.4 \pm 3 \mathrm{mV}$ as measured by Vandrangi et al. under standard cell culture conditions ${ }^{54}$. For E. coli, Soni et al. measured $-47.8 \pm 0.7 \mathrm{mV}$ for cell culture rich medium and $-40.2 \mathrm{mV}$ for cells in a culture deficient medium. They also showed that labelling with a similar fluorescent protein as used in our study only slightly changed the zeta potential to $-45.9 \mathrm{mV}$ in rich culture medium. These values are consistent with the much higher polar surface free energy measured for our $E$. coli strain and confirm that these cells are indeed more negatively charged than the yeast and HEK cells used in this study. The zeta potential, however, is expected to vary by ionic strength and will, therefore, depend on the medium. For medical implant purposes, we are interested in ionic strengths within the physiological conditions, e.g., $1 \times \mathrm{PBS}$, and standard culture medium conditions.

Measurements on pure PDMS gave a very low SFE, originating from dispersive forces only. Therefore, the choice of PDMS as a substrate for cell monolayers is appropriate and since 
the main difference between the two eukaryotic cells and E. coli is in the polar part, this must be due to the cell monolayers themselves. In the following sections, we will assess and compare the adhesion behavior of $S$. cerevisiae and E. coli on silica and gold and evaluate the effect of SFE on their adhesion patterns. Silanized silica will allow to assess the relative effect of the polar and dispersive components. Focus will be on short term adhesion kinetics under flow, long term steady state adhesion and detachment and the effect of SFE on the viscoelastic signatures of the cells. Finally, the surface dependence of HEK cell adhesion will be analysed as an example of eukaryotic mammalian cells.

\subsection{S. cerevisiae and E. coli adhesion on silica}

\subsubsection{S. cerevisiae adhesion on silica}

For clarity, we show only average data points, but all data points are considered for quantifications, including fittings and fit parameters. Figure 1A. displays the average $\Delta f$ (dashed lines) and $\Delta D$ (solid lines) responses of at least three QCM-D experiments for five overtones $\left(5^{\text {th }}, 7^{\text {th }}, 9^{\text {th }}, 11^{\text {th }}\right.$, and $\left.13^{\text {th }}\right)$ acquired with a yeast concentration of $\approx 1.6 \times 10^{5}$ cells $/ \mathrm{ml}$ in $1 \times$ PBS buffer at $37^{\circ} \mathrm{C}$. The $1^{\text {st }}$ and $3^{\text {rd }}$ overtones are left out because they penetrate far into the liquid and therefore, do not accurately represent the cell-surface interactions. All overtones display similar trends in the time dependence of $\Delta f$ and $\Delta D$ and we can distinguish three regimes: Regime I represents cell adhesion under flow while regimes II and III are different phases of the long-term cell-material interactions in stagnant liquid. Only the first $36 \mathrm{~h}$ are shown for a better depiction, while measurements for at least 72 hours are included in the supporting information, Figure S3. In addition, Figure S4 of the Supporting Information shows measurements with lower yeast cell concentrations $\left(3.3 \times 10^{4}\right.$ cells $/ \mathrm{ml}$ and $6.6 \times 10^{4}$ cells $\left./ \mathrm{ml}\right)$ displaying the same features. 

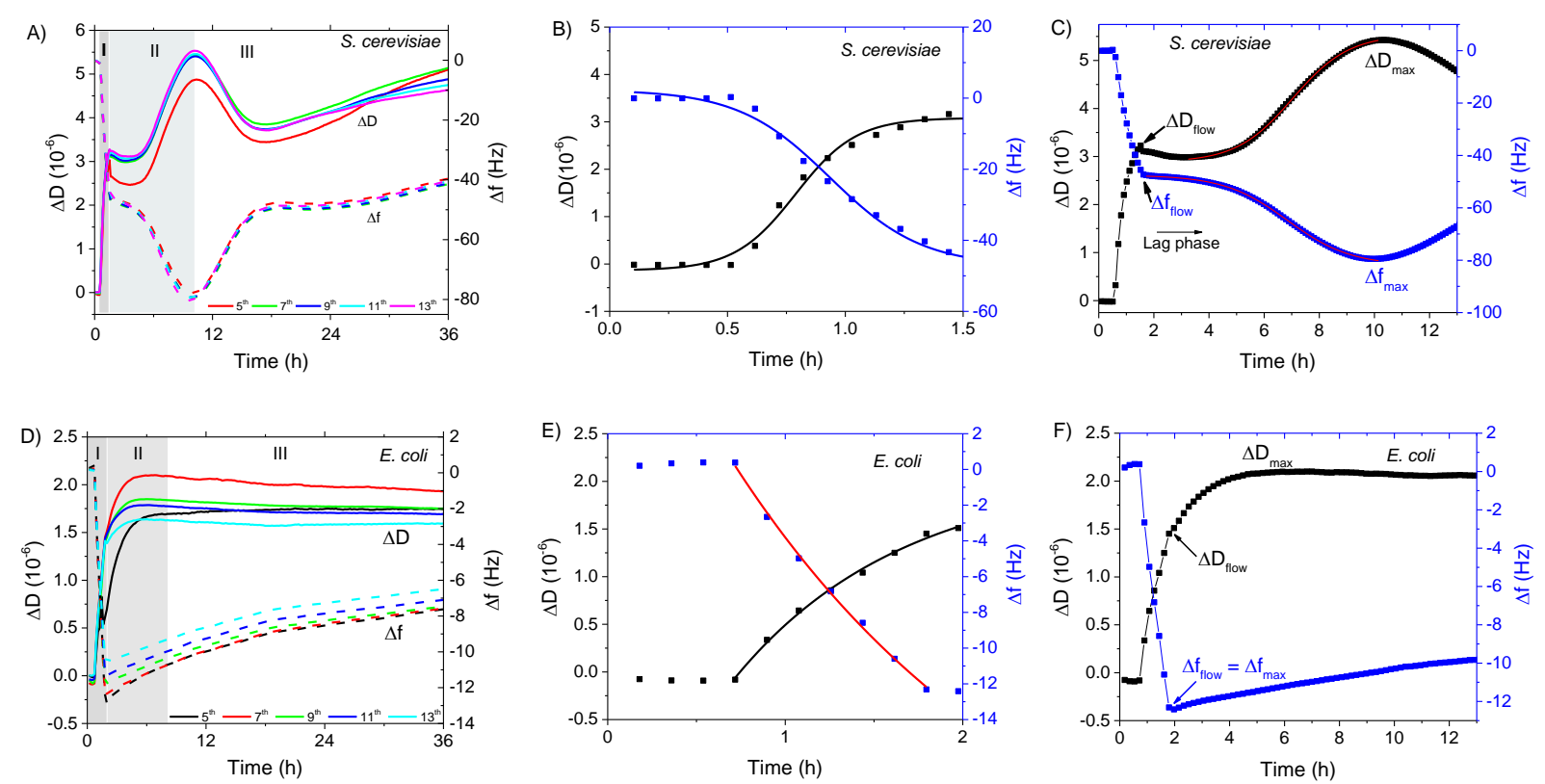

Figure 1. QCM-D monitoring of long-term S. cerevisiae and $\boldsymbol{E}$. coli adhesion under flow and non-flow conditions.

A) Representative $\Delta f$ and $\Delta D$ depicting the first 36 hours for a $1.6 \times 10^{5}$ cells $/ \mathrm{ml}$ S. cerevisiae adhesion on silica.

B) Expanded $\Delta f$ and $\Delta D$ responses and Boltzmann fitting for the $7^{\text {th }}$ overtone up to the end of the flow phase. C)

Expanded $\Delta D$ and $\Delta f$ plots for the $7^{\text {th }}$ overtone showing lag phase and maximum adhesion. D) Plots of $\Delta f$ and $\Delta D$ showing the first 36 hours for a $10^{6}$ cells $/ \mathrm{ml} \mathrm{E.} \mathrm{coli} \mathrm{adhesion} \mathrm{on} \mathrm{silica.} \mathrm{E)} \mathrm{Expanded} \Delta D$ and $\Delta f$ plots and exponential fitting for the $7^{\text {th }}$ overtone showing E. coli adhesion dynamics under flow. F) Expanded $\Delta D$ and $\Delta f$ plots for the $7^{\text {th }}$ overtone showing continuous $\Delta D$ increase to a plateau.

Figure 1B shows expanded plots of $\Delta f$ and $\Delta D$ for the $7^{\text {th }}$ overtone resulting from $S$. cerevisiae adsorption on silica during flow (Regime I), showing a frequency decrease of $48 \mathrm{~Hz}$ and a dissipation increase to $3.2 \times 10^{-6}$. This indicates the adsorption of viscoelastic material on the surface while the cells encounter hydrodynamic stress. The $\Delta f$ and $\Delta D$ data was fitted for 60 minutes of flow using the non-linear Boltzmann regression model (Eq. 2) embedded in the OriginPro $2016^{\circledR}$ software, version b9.3.226 (Northampton, MA, USA). The fits, shown as solid lines, both have $\mathrm{R}^{2} \geq 0.99$.

$\mathrm{Y}=\mathrm{A}_{2}+\frac{A_{1}-A_{2}}{1+\exp \left(t-t_{1 / 2}\right) / \tau}$

Eq. 2 
The dependent variable Y $(\Delta f$ or $\Delta D)$ varies between the limiting values of the initial stable signal, $\mathrm{A}_{1}$ in PBS, and the final signal, $\mathrm{A}_{2}$ after cell addition. The parameter $\mathrm{t}_{1 / 2}$ is the time for which $\mathrm{Y}$ is half-way between $\mathrm{A}_{2}$ and $\mathrm{A}_{1}$, while $\tau$ is the time constant. The $\mathrm{t}_{1 / 2}$ values for $\Delta f$ and $\Delta D$ are respectively $56.2 \pm 1.3$ and $47.3 \pm 1.0 \mathrm{~min}$, while the $\tau$ values are $11.7 \pm 1.3$ and $7.7 \pm$ $0.9 \mathrm{~min}$. The errors are the standard errors of the fit parameters. Since $\mathrm{t}_{1 / 2}$ depends on the initial stabilization time, we corrected for the initial delay time, which is 30 mins for the yeast measurement in Figure 1, thus giving $\mathrm{t}_{1 / 2}$ values of $26.2 \mathrm{~min}$ for $\Delta f$ and $17.3 \mathrm{~min}$ for $\Delta D$. Henceforth, all $\mathrm{t}_{1 / 2}$ values mentioned, including the values in Table 2 are the absolute values obtained from subtracting the initial stabilization time. The sigmoidal nature of $\Delta f$ and $\Delta D$ as a function of time indicates that the adsorption of cells to the surface under flow is positively cooperative, which means that the presence of cells on the surface enhances further cell adsorption, a phenomenon also reported for mammalian cells ${ }^{57,58}$. The $\mathrm{t}_{1 / 2}$ and $\tau$ values for $\Delta f$ are longer in comparison to those for $\Delta D$, indicating that an additional process, such as a change in cellular viscoelasticity, contributes to the $\Delta D$ response. If viscoelasticity does not change with time, the kinetics of $\Delta D$ and $\Delta f$ would be identical ${ }^{29}$. Measurements with lower concentrations also show that the time constants for $\Delta D$ are shorter than for $\Delta f$. Table 2 compares the mean values of the fit parameters and the total $\Delta f$ and $\Delta D$ shifts during flow ( $\Delta f_{\text {flow }}$ and $\Delta D_{\text {flow }}$ ) for the three yeast cell concentrations. The data show that $\Delta f_{\text {flow }}$ and $\Delta D_{\text {flow }}$ increase with increasing concentration while $t_{1 / 2}$ and $\tau$ decrease. Thus, the adhesion level and adhesion rate $(1 / \tau)$ both increase with increasing concentration. 


\section{Table 2}

Surface-dependent $\boldsymbol{S}$. cerevisiae and $\boldsymbol{E}$. coli adhesion, showing the average $\Delta f, \Delta D, \tau$, and $t_{1 / 2}$ values for at least two measurements. Errors represent the standard deviations.

\begin{tabular}{|c|c|c|c|c|c|c|c|c|c|}
\hline & $\begin{array}{l}\text { Cells } \\
10^{4} / \mathrm{ml}\end{array}$ & $\begin{array}{c}-\Delta f_{\text {flow }} \\
(\mathrm{Hz})\end{array}$ & $\begin{array}{c}-\Delta f_{\text {flow }} \\
\mathrm{t}_{1 / 2}(\mathrm{~min})\end{array}$ & $\begin{array}{c}-\Delta f_{\text {flow }} \\
\tau(\mathrm{min})\end{array}$ & $\begin{array}{c}\Delta D_{\text {flow }} \\
\times 10^{-6}\end{array}$ & $\begin{array}{c}\Delta D_{\text {flow }} \\
\mathrm{t}_{1 / 2}(\min )\end{array}$ & $\begin{array}{c}\Delta D_{\text {flow }} \\
\tau(\mathrm{min})\end{array}$ & $\begin{array}{c}-\Delta f_{\max } \\
(\mathrm{Hz})\end{array}$ & $\begin{array}{l}\Delta D_{\max } \\
\times 10^{-6}\end{array}$ \\
\hline \multicolumn{10}{|c|}{ S. cerevisiae } \\
\hline & 16 & $47.3 \pm 6$ & $25.6 \pm 0.8$ & $10 \pm 1.9$ & $3.3 \pm 0.4$ & $18.8 \pm 2$ & $7.0 \pm 1$ & $79 \pm 7.4$ & $5.6 \pm 0.9$ \\
\hline \multirow[t]{2}{*}{ Silica } & 6.6 & $25.4 \pm 0.6$ & $34.7 \pm 0.7$ & $12.9 \pm 0.6$ & $2.7 \pm 0.0$ & $28 \pm 2.5$ & $11 \pm 0.4$ & $39.3 \pm 2.4$ & $2.9 \pm 0.1$ \\
\hline & 3.3 & $18.4 \pm 2.5$ & $38 \pm 0.8$ & $14.5 \pm 0.7$ & $2.0 \pm 0.2$ & $29.5 \pm 2.9$ & $11.7 \pm 1.7$ & $23.6 \pm 2$ & $2.3 \pm 0.1$ \\
\hline Gold & 16 & $37 \pm 4.2$ & $16.8 \pm 0.9$ & $6.2 \pm 0.1$ & $2.3 \pm 0.1$ & $14.7 \pm 0.8$ & $4.5 \pm 0$ & $60.5 \pm 6.4$ & $4.1 \pm 0.1$ \\
\hline $\begin{array}{l}\text { Silanized } \\
\text { Silica }\end{array}$ & 16 & $11.2 \pm 0.8$ & $9.8 \pm 1.1$ & $6.2 \pm 0.8$ & $0.4 \pm 0.1$ & $5.1 \pm 1.2$ & $1.9 \pm 0.6$ & $41 \pm 7.1$ & $2.6 \pm 0.7$ \\
\hline \multicolumn{10}{|l|}{ E. coli } \\
\hline Silica & 100 & $14.3 \pm 1.6$ & N/A & $94.3 \pm 15$ & $1.6 \pm 0.2$ & N/A & $61.7 \pm 6.2$ & $14.3 \pm 1.6$ & $2.3 \pm 0.3$ \\
\hline Gold & 100 & $33.5 \pm 4$ & N/A & $11.5 \pm 3.1$ & $1.4 \pm 0.3$ & N/A & $17.2 \pm 7.4$ & $33.5 \pm 4$ & $2.1 \pm 0.3$ \\
\hline $\begin{array}{l}\text { Silanized } \\
\text { Silica }\end{array}$ & 100 & $18.8 \pm 0.8$ & N/A & N/A & $1.5 \pm 0.3$ & N/A & N/A & $18.8 \pm 0.8$ & $3.2 \pm 0.9$ \\
\hline
\end{tabular}

Regime II is characterized by two phases as shown in Figure 1C. During the first phase, $\Delta f$ remains mostly constant, indicating that cells maintain a minimal contact area and weak coupling with the sensor surface. Such a phase, with limited changes in cell adhesion has been reported for mammalian cells as the 'lag phase ${ }^{34,57}$. Following the lag phase, frequency signal drops sharply and non-linearly to $-80 \mathrm{~Hz}\left(\Delta f_{\max }\right.$, Figure 1C). The behavior of the frequency shift in the second phase of regime II also follows a Boltzmann behavior, consistent with Eq. 2 $\left(\mathrm{t}_{1 / 2}=6.8 \mathrm{~h}, \tau=1.2 \mathrm{~h}, \mathrm{R}^{2}=0.999\right)$. This indicates that after the lag phase, more cell mass strongly attaches to the surface $59,60,8$, again with a cell-cell cooperativity effect ${ }^{61}$. We can exclude the possibility that data are affected by cell proliferation during measurements because the medium is nutrient free, and cells had been washed in pure PBS.

Interestingly, the behavior of $\Delta D$ is not reciprocal to that of $\Delta f$ in the first phase of regime II: After $\Delta D$ reaches a maximum by the end of flow $\left(\Delta D_{\text {flow }}\right)$, it decreases considerably 
in time, while $\Delta f$ remains mostly constant. This decrease in $\Delta D$ confirms that, the cell layer becomes less dissipative during the lag phase and suggests that there is a re-organization of the cell's cytoskeleton ${ }^{5}$. Following the $\Delta D$ decrease, $\Delta D$ increases sharply according to Eq. $2\left(\mathrm{R}^{2}\right.$ $\left.=0.999, \mathrm{t}_{1 / 2}=7.0 \mathrm{~h}, \tau=1 \mathrm{~h}\right)$ to a maximum $\left(\Delta D_{\max }\right)$, which coincides in time with the maximum in $\Delta \mathrm{f}\left(\Delta f_{\max }\right)$ (Figure 1C). Table 2 shows the average values of $\Delta f_{\max }$ and $\Delta D_{\max }$, for the three cell concentrations on silica, confirming that surface coverage increases with cell concentration.

Finally, in regime III, $\Delta f$ and $\Delta D$ decrease in magnitude, suggesting that the cell-surface contact is gradually lost, and detachment occurs. For the $1.6 \times 10^{5}$ cells $/ \mathrm{ml}$ concentration, the average detachment time is $12 \pm 2 \mathrm{~h}$. The detachment time is the period spanning the introduction of cells to the surface and the local $\Delta f$ minimum $\left(\Delta f_{\max }\right)$. The detachment time increases with decreasing concentration as depicted in Figure S4 of the Supporting Information. At low concentrations, cell-cell separation is larger, thus cells can establish more adhesion bonds, resulting in stronger adhesion strength ${ }^{8}$, thus longer cell retention. This result is a significant finding, as it reveals that yeast adhesion is followed by a non-invasive, timedependent detachment. This phenomenon provides fundamental insight regarding many natural processes such as biofilm formation and cell release mechanisms in nutrient-free environments. Thus, it would be interesting to probe this phenomenon in different media and with other eukaryotic cells to understand the complex cell detachment mechanisms in, for instance, cancer metastasis.

\subsubsection{Adhesion of E. coli on silica}

Figure 1D shows typical frequency and dissipation plots of the $5^{\text {th }}$ to the $13^{\text {th }}$ overtone measured for an E. coli concentration of $10^{6}$ cells/ml displaying three regimes I, II, and III. Regime I represent cell adhesion under flow, Regime II spans the end of flow to the maximum $\Delta D$, while the rest of the profile is regime III. During flow, $\Delta D$ increases while $\Delta f$ becomes more negative 
due to cell adsorption on the silica surface (Figure 1E). The time dependence of $\Delta f$ (and $\Delta D$ ) is exponential according to Eq. 3 ( $\mathrm{R}^{2} \geq 0.99$ for all fits).

$$
\mathrm{Y}=\mathrm{Y}_{0}+\operatorname{Aexp}(-t / \tau) \quad \text { Eq. } 3
$$

Where $\mathrm{Y}$ represents $\Delta f$ or $\Delta D, \mathrm{Y}_{0}$ the horizontal asymptote of the fit function, A the amplitude and $\tau$ the time constant. The time constants are $105 \pm 3.3 \min$ for $\Delta f$ and $57 \pm 1.3$ min for $\Delta D$ while the total $\Delta f$ is $\approx 12.4 \mathrm{~Hz}$ with a corresponding $\Delta D$ of $1.5 \times 10^{-6}$. The $\mathrm{Y}_{0}$ value for $\Delta f$ is $-26.6 \pm 0.6 \mathrm{~Hz}$, while for $\Delta D$, this value is $2.1 \pm 0.03 \times 10^{-6}$. All errors are standard errors and the relatively small parameter errors, together with the high $R^{2}(\geq 0.99)$ indicates that Eq. 3 is a good approximation for describing E. coli adsorption on silica. The exponential profile suggests that E. coli adsorption is not positively cooperative. Also, compared with yeast adhesion under flow, E. coli adsorption is much slower, and this can be attributed, in part, to the higher zeta potential and surface free energy of the E. coli cells (Table 1). Following the addition of cells, the magnitude of $\Delta f$ decreases, while $\Delta D$ keeps increasing exponentially for nearly 3 hours (regime II) before reaching a plateau (Figure 1F). This behavior is in contrast to the yeast adhesion profile shown in Figure 1A. The decreasing magnitude of $\Delta f$ indicates that the bacteria desorb from the silica surface. On the other hand, the continuous dissipation increase shows that after cells enter into contact with the surface, coupling between the cell membrane and the surface is maintained through soft and strongly energy-dissipating structures that become less tightly bound with time. Prokaryotic cells often have soft and tiny appendages on their surfaces, including flagella, fimbriae and pili, which may play a significant role in cell adhesion behaviour. The flagella of $E$. coli, for instance, have been shown to moderate cell adhesion in a surface-dependent manner: flagella adhere poorly to hydrophilic surfaces and inhibit cell binding ${ }^{46}$. The continuous dissipation increase can therefore be attributed to the soft and flexible structures on the cell wall and their increasing Brownian motion upon desorption 
as well as the thin liquid film between the bacteria and the surface due to lose coupling ${ }^{27}$. In regime III, $\Delta D$ decreases slightly and remains constant in the long term as $\Delta f$ continues to decrease in magnitude, thus indicating continuous, but gradual cell desorption.

\subsection{SFE and S. cerevisiae adhesion}

To evaluate the effect of SFE on yeast adhesion, a $1.6 \times 10^{5}$ cells $/ \mathrm{ml}$ suspension was measured on gold, silica and silanized silica. Figure $\mathbf{2 A}$ compares the frequency plots for representative measurements on these materials over a period of 80 hours, with a logarithmic scaling of the time axis. Figure 2B shows the corresponding dissipation signals. In both cases, the cell adhesion regimes (I, II, II) described for silica in Section 3.2.1 are clearly visible.

At the end of regime $\mathrm{I}$, the magnitudes of $\Delta f$ and $\Delta D$ are smaller for gold ( $\Delta f=-37 \pm 4.2$ $\left.\mathrm{Hz}, \Delta D=2.3 \pm 0.1 \times 10^{-6}\right)$ and silanized silica $\left(\Delta f=-11.2 \pm 0.8 \mathrm{~Hz}, \Delta D=0.4 \pm 0.1 \times 10^{-6}\right)$ than for the unmodified silica with $\Delta f=-47 \pm 6 \mathrm{~Hz}, \Delta D=3.3 \pm 0.4 \times 10^{-6}$. Figure 2C compares $\Delta f_{\text {flow }}$ and $\Delta D_{\text {flow }}$ for an average of at least two measurements on the three surface types as a function of SFE. As shown, the magnitude of both parameters decreases from silica to gold and then to silanized silica. Thus, under flow, yeast adhesion increases with increasing SFE. The effect of SFE seems to be mostly driven by its polar component, which is $37.9 \mathrm{mNm}^{-1}$ for silica, $9.0 \mathrm{mNm}^{-1}$ for gold, and only $6.6 \mathrm{mNm}^{-1}$ for silica after silanization.

During flow, both the frequency and dissipation shifts follow a similar sigmoidal trend as described for silica (Eq 2), with the fit parameters summarized in Table 2. Figures 2E and 2D show $\mathrm{t}_{1 / 2}$ and $\tau$ for $\Delta f$ and $\Delta D$ as a function of SFE, showing that both time parameters increase with SFE. Consequently, adhesion rate, $1 / \tau$ increases with decreasing SFE. However, because the cell adsorption rate does not positively correlate with the adhesion levels $\left(\Delta f_{\text {flow }}\right)$, we hypothesise that the adhesion rate is rather driven by hydrophobic forces, which positively 
correlate with surface hydrophobicity as determined from water contact angles (Table 1). Hydrophobic forces are long-range, up to hundreds of nanometres ${ }^{62,63}$. Therefore, they must play a significant role in modulating the double layer repulsion $(<10 \mathrm{~nm})$, thus enhancing the adhesion rate.
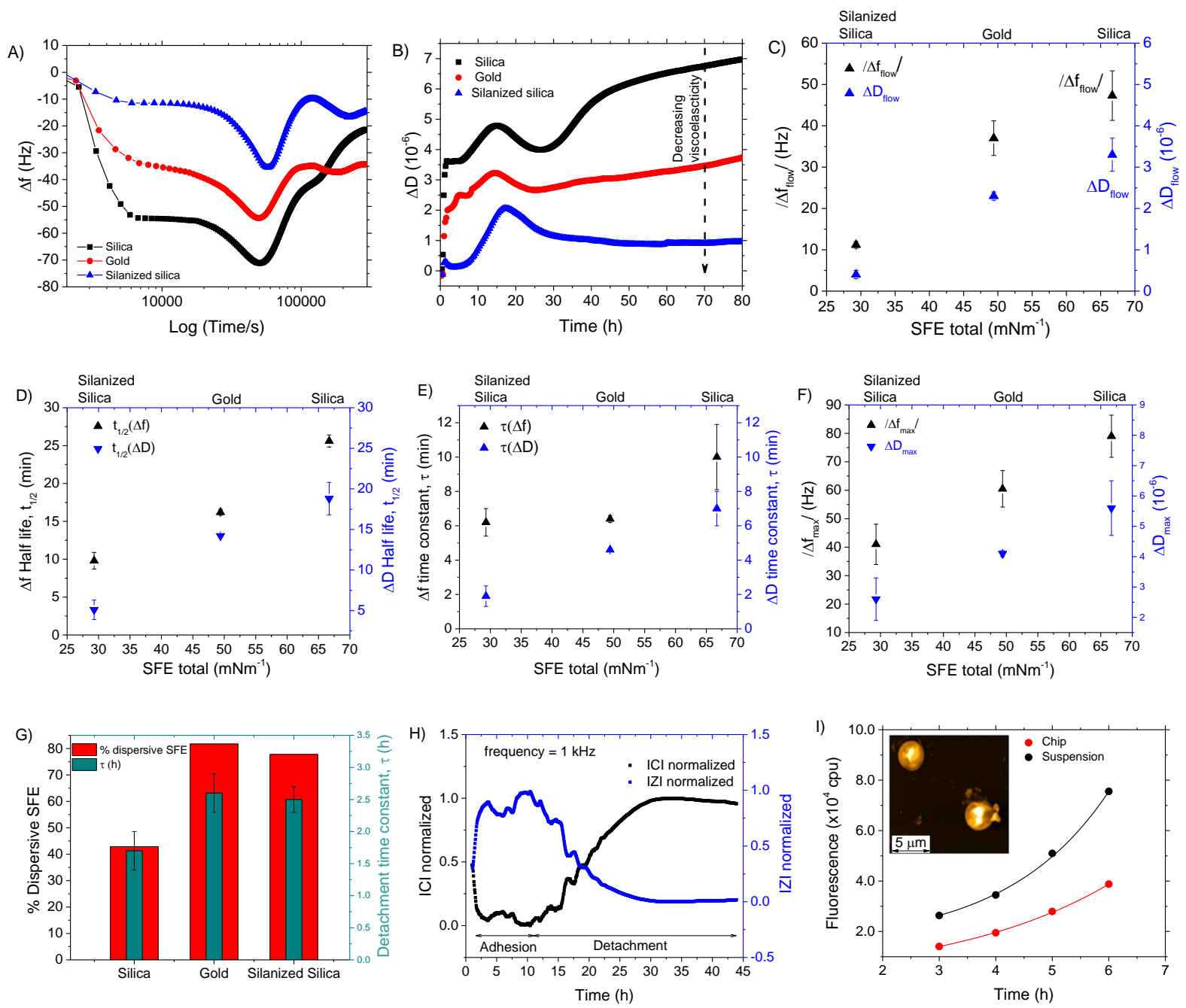

Figure 2. Surface dependent yeast cell adhesion monitoring. Time evolution of $\Delta f(A)$ and $\Delta D(B)$ showing cell adhesion in the presence of flow and at steady state as well as during long-term cell detachment. C) Total $\Delta f$ and $\triangle D$ responses during flow as a function of SFE. D) SFE dependent $t_{1 / 2}$ and $\tau(E)$ for $\Delta f, \Delta D$. F) Surface dependent $\Delta f_{\max }$ and $\left.\Delta D_{\max } . G\right)$ Dependence of yeast cell retention on the dispersive fraction of the SFE. H) Time-dependent capacitance and impedance response depicting yeast cell adhesion and detachment. I) Viability test showing increasing yeast cell activity with time. Insert: AFM image of yeast cells on gold after measurement displaying preserved structural integrity. 
In regime II, $\Delta f_{\max }$ and $\Delta D_{\max }$ are also smaller compared to the silica values; $60.5 \pm 6.4$ $\mathrm{Hz}$ and $4.1 \pm 0.1 \times 10^{-6}$ for gold, $41 \pm 7.1 \mathrm{~Hz}$ and $2.6 \pm 0.7\left(10^{-6}\right)$ for silanized silica (Table 2). Figure $2 \mathbf{F}$ displays the average $\Delta f_{\max }$ and $\Delta D_{\max }$ as a function of SFE, showing an increase in both parameters with increasing SFE. Furthermore, $\Delta f$ and $\Delta D$ show a recovery behavior for all three surfaces, revealing that yeast cells detach at longer time scales. There is a remarkable difference in the detachment of yeast from silica as compared to the two other surfaces. On silica, $\Delta f$ recovers by about $75 \%$, while for gold and silanized silica $\Delta f$ recovers to its end-offlow value (end of regime I).

The $\Delta f$ recovery pattern is associated with the dispersive fraction of the SFE, which is the ratio of the dispersive component to the total. In percentages, these values are $81.8 \%$ (gold), $78.9 \%$ (silanized silica) and $42.9 \%$ (silica). Also, the detachment time constant, obtained by fitting Eq. 2 to the first 14 hours after maximum cell adhesion $\left(R^{2} \geq 0.999\right.$ in each case) increases for a higher percentage of dispersive SFE, meaning that the detachment rate decreases (Figure 2G). A high percentage of dispersive forces reflect a strong relative contribution of short-range attractive (van der Waals) forces to the overall cell-surface interactions, which in turn promotes cell retention. These results agree with the extended theory of Derjaguin, Landau, Verwey and Overbeek (XDLVO), which asserts that initial adhesive contact between cells and surfaces is controlled by double-layer repulsive forces and hydrophobic forces, while stable adhesion is driven by van der Waals forces ${ }^{64,65,57}$.

Comparing the long term $\Delta D$ changes between the surfaces, Figure $\mathbf{2 B}$ also shows remarkable differences. For instance, after 70 hours (dashed arrowed line), $\Delta D$ for silica, gold and silanized silica are respectively, $6.8 \times 10^{-6}, 3.510^{-6}$ and $0.9 \times 10^{-6}$, which indicates that the viscoelasticity of the cell layer decreases with decreasing SFE. 
Also, impedance and capacitance analysis, used as a complementary method showed that S. cerevisiae undergo time-dependent detachment. As shown in Figure $\mathbf{2 H}$, the capacitance decreases to a minimum (with a maximum in the impedance) after approximately $11 \mathrm{~h}$ due to cell adhesion. Thereafter, the capacitance increases, thus indicating that cells detach. This can be explained from the point of view that the total capacitance at the electrode-liquid interface without cells is the intrinsic electrode capacitance. For each cell that adsorbs on the electrode, a capacitive layer is formed and the total capacitance, $\mathrm{C}_{\mathrm{T}}$ of the cell and electrode system can be considered as two capacitors in series $\left(1 / \mathrm{C}_{\mathrm{T}}=1 / \mathrm{C}_{\text {cell }}+1 / \mathrm{C}_{\text {electrode }}\right)$. As cells progressively adhere to the electrode, a parallel combination of such series capacitors results in a decrease in the total capacitance ${ }^{52}$. Upon cell detachment, the contribution by the cells diminishes and the electrode capacitance is recovered. Therefore, impedance analysis confirms the cell detachment and its timescale, consistent with the data obtained with QCM.

Finally, we assessed the viability and structural integrity of the cells over the course of such long-term measurements. Figure 2I presents the results obtained from the cell suspension and the chip after 96 hours of measurement on gold, showing an exponential increase in resorufin fluorescence as a function of incubation time, resulting from the reduction of resazurin by life cells, with no change in the PBS-only control sample (not shown). This proves that the cells are still metabolically active after 4 days. The insert in Figure 2I shows an AFM image of the gold chip after long-term yeast adhesion monitoring, which clearly displays yeast cells of $\approx 3 \mu \mathrm{m}$ diameter, the typical size of $S$. cerevisiae.

\subsection{Surface energy and E. coli adhesion}

Figures $3 \mathrm{~A}$ and $3 \mathbf{B}$ show (in log scale) the time-dependent $\Delta f$ and $\Delta D$ in response to the adhesion of $10^{6}$ cells $/ \mathrm{ml}$ E. coli on silica, gold and silanized silica. Under flow, for silica and gold, $\Delta f$ shows an exponential decay according to Eq. 3 to plateau values of $12.5 \mathrm{~Hz}$ (silica) 
and $-34.5 \mathrm{~Hz}$ (gold), indicating clearly that E. coli adhesion is much higher on gold than on silica. With regards to the adhesion kinetics under flow, the time constant of $\Delta f$ is shorter for gold than for silica (Table 2). This shows that E. coli adsorbs faster on gold, than on silica.
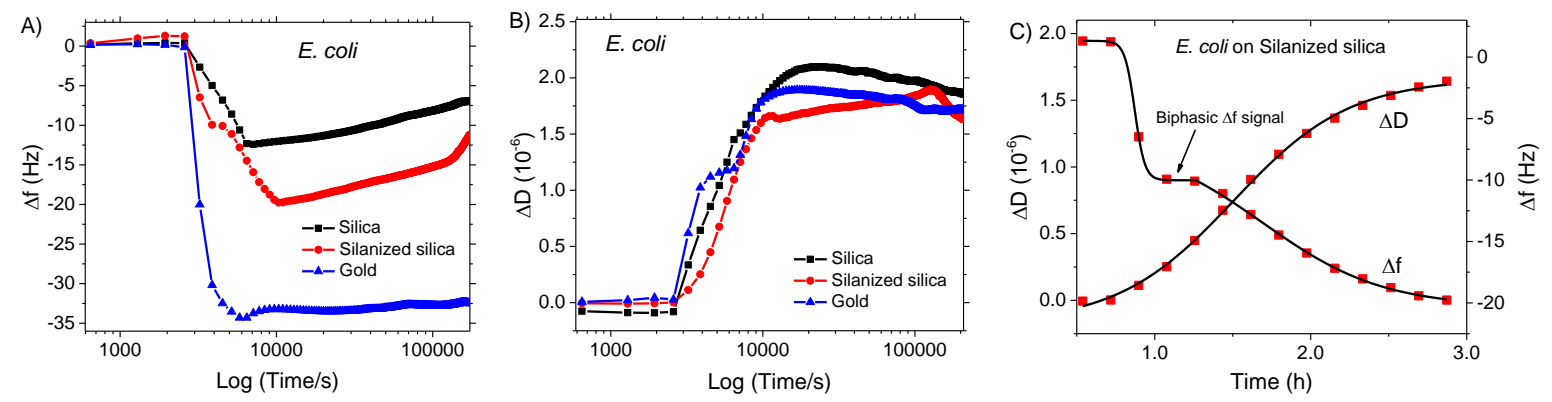

D)
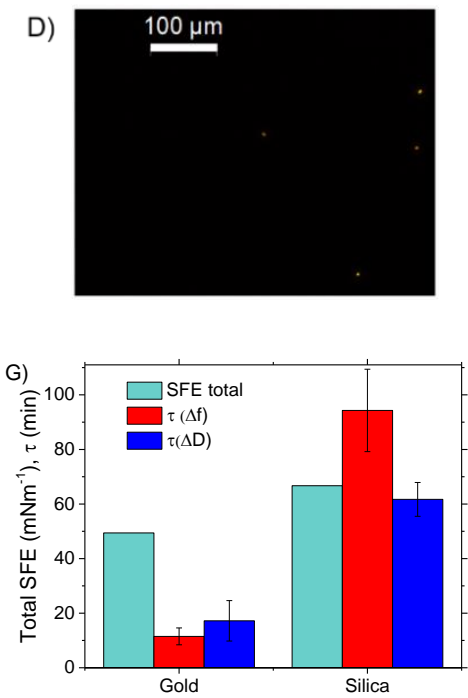

E)
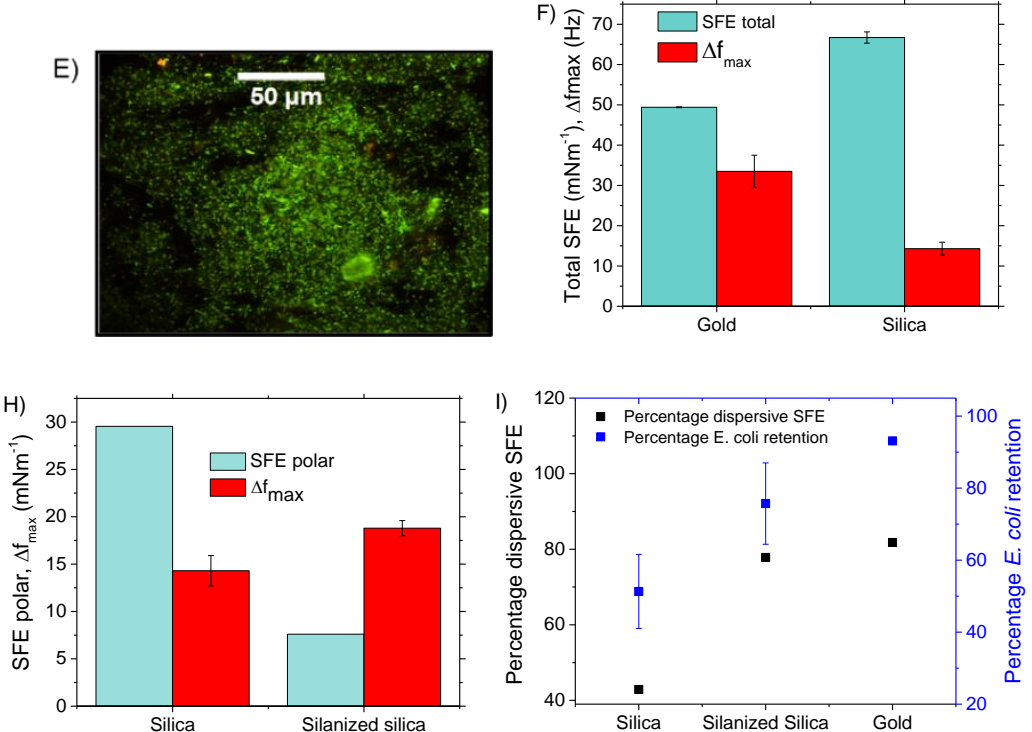

Figure 3. Surface free energy dependent $\boldsymbol{E}$ coli adhesion. Logarithmic time evolution of $\Delta f(A)$ and $\Delta D(B)$ showing cell adhesion under flow and steady state conditions. C) Expanded $\Delta f$ and $\Delta D$ plots displaying a two-stage adhesion response on silanized silica. Fluorescence images of silica $(D)$ and gold $(E)$ sensor surfaces after a longterm adhesion monitoring. F) Maximum $\Delta f$ as a function of SFE. G) Surface energy dependent $\Delta f$ and $\Delta D$ time constant. H) Silanization decreases the polar component of the SFE and enhances E. coli adhesion. I) E coli cell retention as a function of the dispersive SFE fraction. In panels $F-I$, all data points are averages of three measurements and error bars correspond to standard deviations.

For silanized silica, $\Delta f$ shows an initial fast change $\left(\mathrm{t}_{1 / 2}=7.3 \mathrm{~min}, \tau=1.9 \mathrm{~min}\right)$ followed by a more gradual change with $\mathrm{t}_{1 / 2}=55 \mathrm{~min}$ and $\tau=12.9 \mathrm{~min}$. The parameters are obtained with a sigmoid fit function according to Eq. $2\left(\mathrm{R}^{2}>0.99\right)$. The total $\Delta f$ change is $\approx-19 \mathrm{~Hz}$, which is 
in between the values for pure silica and gold. Analysis of the $\Delta f$ time constant for the silanized silica surface is not straightforward due to the two-step process. However, the overall $\Delta f$ and $\Delta D$ profiles suggest a much faster adsorption rate on silanized than on bare silica. The two-step frequency profile indicates a transition within the adhesion process, which can be attributed to interfacial rearrangements at the bacteria-substrate interface. Here, the appendages of $E$. coli, such as their flagella probably play a major role $\mathrm{e}^{46,66}$. The higher adhesion level of E. coli on silanized silica compared to pure silica agrees with Friedlander et al., who reported a positive correlation between $E$. coli adhesion and the surface hydrophobicity of self-assembled monolayers of thiols with different end-groups on gold films ${ }^{46}$. However, from our measurements, higher adhesion is measured on gold $\left(\mathrm{CA}=61^{\circ}\right)$ compared to silanized silica $\left(\mathrm{CA}=82^{\circ}\right)$, thus indicating that other surface factors, besides surface hydrophobicity account for the E. coli adhesion, for instance, surface charge, zeta potential, surface roughness and constituent elements at the surface ${ }^{36}$.

In regime II, the magnitude of $\Delta f$ for gold is the highest, with minimal changes over time, while it clearly decreases for silica and silanized silica as the dissipation increases to a maximum value for all three surfaces. During regime III, $\Delta D$ decreases to a plateau for all surface while the frequency signal continues to decrease markedly over time for silica and silanized silica with little or no change for gold. This confirms that in long term, at the scale of days, cells remain bound on gold, but not on silica and silanized silica. Figures $3 D$ and $\mathbf{3 E}$ show the fluorescence images of the rinsed silica and gold surfaces, respectively, after measurement and clearly display green fluorescence from the gold surface and no fluorescence from the silica surface because of cell detachment. This proves that the steady and high $\Delta f$ signal measured for gold is indeed due to bound E. coli, the structural integrity of which is also preserved as displayed by the brightfield optical image in Figure S5. 
With regards to SFE, we show that a high surface free energy surface (silica) hinders $E$. coli adhesion (Figure 3F, and Figure 3G) probably due to the high SFE and zeta potential of the $E$. coli cells themselves. Specifically, the polar component plays a major role in preventing E. coli adhesion, which also possess a high polar component (Figure 3H). On the other hand, the dispersive component promotes adhesion and long-term retention. Figure 3I displays E. coli retention at $t=24 \mathrm{~h}$ as a function of the dispersive fraction of the SFE. The percentage retention was calculated as the ratio of $\Delta f$ at $24 \mathrm{~h}, \Delta f_{24 h}$, to the maximum value of $\Delta f$ following cell addition, $\Delta f_{\max }$ : percentage retention $=\Delta f_{24 h} / \Delta f_{\max } \times 100$. As shown, the retention of $E$. coli increases with the dispersive fraction of the SFE. This can be attributed to less electrostatic repulsion and strong van der Waals interactions between the dispersive surface and the cells.

\subsection{Cytoskeletal changes accompanying S. cerevisiae and E. coli adhesion}

\subsubsection{Cytoskeletal changes and S. cerevisiae adhesion}

We also assessed the time dependent changes in the internal cellular organization accompanying S. cerevisiae and E. coli adhesion under flow and non-flow conditions as a function of surface free energy. Internal cellular organization correlates with the viscoelasticity of the cells; the more organized the cellular interior, the stiffer the cells ${ }^{5,34}$. Therefore, such analysis highlights cell adhesion mechanisms from a cytoskeletal perspective and the dependence of these mechanisms on substrate SFE. Figure 4A displays a df (dissipation versus frequency) plot for the $7^{\text {th }}$ overtone with $1.6 \times 10^{5}$ cells/ml-yeast concentration measured on silica. The three regimes described for yeast adhesion (I, II, III) are indicated in the plot. As shown, for regime I, the df plot exhibits a monotonic behavior with a decreasing slope, indicating that yeast cells undergo small internal changes (becoming stiffer) in their cytoskeleton upon contact with the surface during this regime. In regime II, the slope of the df plot is mostly linear, except for a gentle increase that follows a sharp, but brief drop in the beginning (arrowhead). A constant slope indicates that the mass loading is associated with 
homogeneous viscoelastic properties, thus, no cytoskeletal changes are taking place. The behavior of the df plot here is a characteristic signature of cell spreading ${ }^{8}$. Finally, in regime III, the df plot exhibits a linear and nearly symmetrical reversal, which represents loss of cellsurface contact due to cell de-adhesion. The slope of the df plot subsequently increases sharply, but because at this point $\Delta f$ is at a plateau, this is related to increased viscoelasticity of the overlayer as a whole.
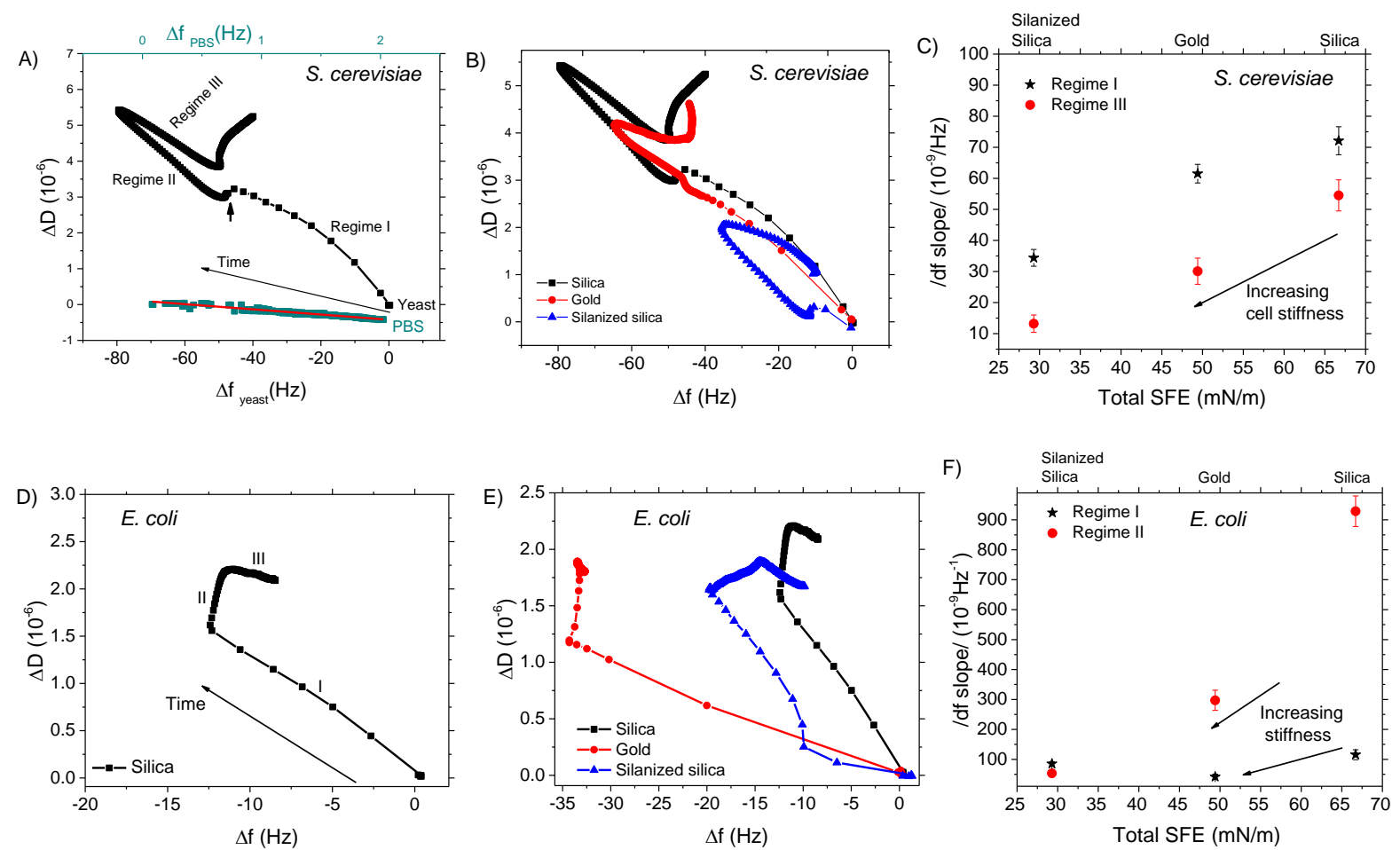

Figure 4. SFE dependent adhesion fingerprints of S. cerevisiae and $\boldsymbol{E}$. coli. A) df plots for S. cerevisiae on silica for a period of 48 hours (upper curve) and $1 \times P B S$ on silica (lower curve). B) df plot for $S$. cerevisiae adhesion on gold, silica and silanized silica showing a decrease in the viscoelasticity of the cells from silica, to gold to silanized silica. C) Slope of df plots, in absolute values as a function of SFE, showing a decrease in cell stiffness from regime I to regime III and an increase in cell stiffness for each phase with decreasing SFE. D) df plot for E. coli adhesion on silica for a period of 24 hours. E) df plot for E. coli adhesion on gold, silica and silanized silica showing a decrease in the viscoelasticity of cells on the silanized silica compared to silica and highlighting the two-step adhesion process on silanized silica. F) Absolute values of df slope compared between the three surfaces for adhesion under flow (regimes I), and the initial detachment in stagnant liquid (regimes II). In panel C) and F) the data points were determined from three separate measurements and the error bars represent the standard deviations. 
Such df plot profiles are independent of cell concentration, confirming that these are indeed the pure cell-material adhesion fingerprints of $S$. cerevisiae (See Figure S4, Supporting Information for data on other concentrations). From the control experiment with pure PBS, the df plot (Figure 4A, lower curve) gives a straight line, confirming that the changes in the df plot for yeast are indeed due to cytoskeletal changes. Overall, the df slope is different for each regime, which indicates that the $S$. cerevisiae cells exhibit different viscoelastic states in these regimes.

Figure 4B shows the comparative df plots for yeast adhesion on all three materials. The different regimes are clearly distinguishable, and the adhesion fingerprints are markedly different between the three surfaces. As a common trend, the overall slope is lower for regime I than regime II, while the slope of regime III is the lowest. An important observation is that the detachment phase (Regime III) involves a transition from a less stiff to a stiffer cell layer, which may provide useful information on the detachment mechanism. Figure 4C displays the SFE dependence of the absolute slope of df for the initial adhesion phase under flow (regime I) and the detachment phase (regime III). For both regimes, the slope of the fingerprint plots clearly increases with increasing SFE, from silanized silica, through gold, to pure silica. This shows that cells behave stiffer on surfaces with low surface free energy.

\subsubsection{Cytoskeletal changes and E. coli adhesion}

Figure 4D displays a df plot for E. coli $\left(1.0 \times 10^{6}\right.$ cells $\left./ \mathrm{ml}\right)$ on silica for a period of 24 hours. The parts of the profile labelled I, II and III correspond to the regimes defined in Section 3.2.2. Figure $4 \mathbf{E}$ shows the comparison of df plots for all three surfaces. For gold and silica, the slope of the df plots increases from phase I to phase II, showing that on each surface the cell layer becomes increasingly energy dissipating. The absolute energy dissipation and the df slope in each phase is smaller for gold than silica, thus the cells are stiffer on gold than on silica. 
Furthermore, the silanized version of silica also displays lower df slopes than the unmodified version, indicating that the reduced SFE makes the bound cells less viscoelastic. To illustrate the correlation between SFE and viscoelasticity, Figure 4F shows the df slopes of regimes I and II, in absolute values as a function of SFE. The slope of regime I for silanized silica is a rough approximation due to its biphasic nature. Nonetheless, the slopes are smaller for silanized silica and gold compared to silica within both regimes.

\subsection{Surface dependent adhesion of HEK cells}

In this study, we used S. cerevisiae as a model organism for eukaryotic cells as explained in Section 2.2. However, it displays important structural difference with mammalian cells, which are the most relevant cells in the case of medical implants. Therefore, we performed additional adhesion experiments on Human Embryonic kidney cells as an example of a mammalian cell on the three surfaces used for yeast and E. coli measurements. Similar to measurements with yeast and E. coli, HEK cells were centrifuged to completely remove the medium and thus allowing to study the pure cell-material adhesion interactions. The concentrations for measurement were $\approx 1.6 \times 10^{5} \mathrm{cell} / \mathrm{ml}$, similar to the yeast concentrations.

Figure 5a shows the dissipation and frequency plots obtained from a representative HEK adhesion measurement on silica over a period of 36 hours with three regimes, I, II and III identified similar to the regimes found with yeast in Section 3.2.1. During cell addition (Regime I), the frequency shift decreases to $\approx-60 \mathrm{~Hz}\left(\Delta f_{\text {flow }}\right.$, Figure $\left.5 \mathbf{b}\right)$, while the dissipation increases to $5.8 \times 10^{-6}\left(\Delta D_{\text {flow }}\right.$, Figure $\left.5 \mathbf{b}\right)$. Following cell addition, in stagnant liquid (regime II), the frequency further decreases to $72 \mathrm{~Hz}\left(\Delta f_{\max }\right)$, with a dissipation increase to $6.5 \times 10^{-6}$ $\left(\Delta D_{\max }\right)$. Finally, in regime III, the frequency recovers alongside the dissipation. Overall, the adhesion behaviour of HEK cells on silica closely resembles that of yeast described in Section 
3.2.1, both involving, for instance, a spreading phase in regime II and an S-shaped detachment phase.
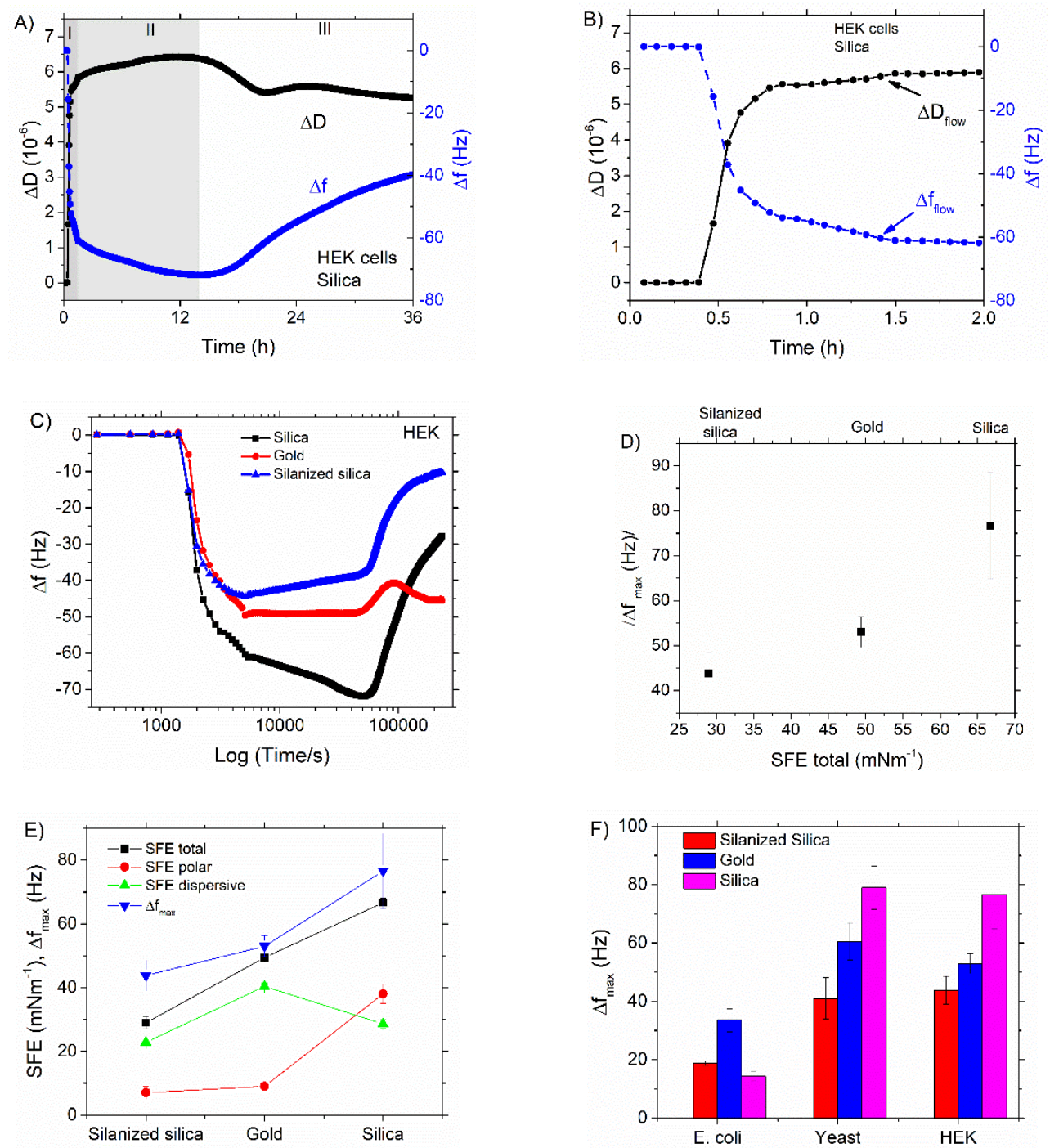

Figure 5. QCM-D monitoring of long-term HEK cell adhesion and detachment. A) $\Delta f$ and $\Delta D$ plots from a representative measurement depicting the first 36 hours of HEK cell adhesion on silica. B) Expanded $\Delta f$ and $\Delta D$ responses for the $7^{\text {th }}$ overtone up to the end of the flow phase. C) Surface dependent $\Delta f$ comparing HEK cell adhesion on silica, gold and silanized silica. D) Surface dependent $\Delta f_{\max }$ representing maximum cell adhesion and showing an increase in cell adhesion as a function of surface free energy. E) Correlation between surface free energy and HEK cell adhesion, displaying a predominant role of the polar surface free energy on HEK cell adhesion on silica. F) Surface dependent adhesion of E. coli, yeast and HEK cells demonstrating a common trend for yeast and HEK cells, with the adhesion of both cells highest on the polar silica surface and minimum on the silanized surface, while E. coli adhesion displays the opposite trend: lowest adhesion on silica, which increases upon silanization. 
For analysing the surface-dependence of HEK cell adhesion, we focus on the frequency plots, displayed in Figure 5C. The total frequency shifts during flow, $\Delta f_{\text {flow }}$ are $-60 \mathrm{~Hz}$ for silica, -50 $\mathrm{Hz}$ for gold and $-45 \mathrm{~Hz}$ for silanized silica, thus showing clearly that the adhesion of HEK cells under flow is surface dependent. A major difference of interest in the adhesion patterns compared between the surfaces shows up in regime II, in which the frequency further shifts significantly for silica compared to gold and silanized silica. This suggests that silica promotes cell adhesion and spreading compared to gold and siliconized silica. It is unlikely that the further shift on silica is due to cell proliferation for two reasons: First the cells were washed in pure $1 \times \mathrm{PBS}$ without nutrients. Secondly, in the case of proliferation, this would also be observed on the other surfaces as their properties allow for cell growth. For instance, as shown in Figure S2, the water contact angle and SFE of the cell culture flask, which is optimized for cell growth are more similar to those of gold than silica.

With regards to surface free energy, Figure 5D displays the maximum frequency shift resulting from HEK cell adhesion as a function of surface free energy. The data points represent the average values from four separate measurements, while the error bars are the standard deviations. As shown, HEK cell adhesion increases with increasing surface free energy. As depicted in Figure 5E, HEK cell adhesion is promoted by a high polar SFE contribution. These results are consistent with findings by Nakamura et al., who reported that the adhesion of mouse osteocyte-like cells to hydroxyapatite was predominantly controlled by the polar SFE ratio ${ }^{36}$. According to their studies, hydroxyapatite surfaces with higher polarization capacities (due to a higher hydroxide ion content) displayed a higher SFE polar ratio compared to conventional hydroxyapatite and promoted accelerated cell adhesion and spreading than the conventional ones.

Figure 5F compares the adhesion of the three cell types on the three surfaces. Data points represent the average of at least three measurements and the errors are the standard deviations. 
As shown, yeast and HEK display high adhesion on the highly polar silica surface, on which $E$. coli adhesion is minimal, thus, confirming that a high polar surface free energy enhances the adhesion of these eukaryotic models and hinder E. coli adhesion. This suggests that SFE analysis of both cells and surfaces is a useful means of tuning surfaces to inhibit bacteria adhesion on implants while promoting eukaryotic cell adhesion. Most importantly, relevant to implants are specific bacteria that are prevalent for causing implant infections, such as Staphylococcus aureus, which is reported as the leading cause of orthopaedic surgical site infections and periprosthetic joint infections according to ref. 14. S. aureus is hydrophilic ${ }^{67}$, with a zeta potential in the range of $-47 \mathrm{mV}(\mathrm{pH} 6.5)$ to $-37 \mathrm{mV}(\mathrm{pH} \mathrm{9.5})^{68}$. Also, and interestingly, the surface free energy of S. aureus as measured by Gerson and Scheer ${ }^{69}$ gave a value of $69.7 \mathrm{mNm}^{-1}$, which is very close to our E. coli value of $68.0 \mathrm{mNm}^{-1}$ displayed in Table 1. Such cells may therefore display the adhesion patterns of E. coli, meaning that while a highly polar surface promotes mammalian cell adhesion, they are likely to inhibit $S$. aureus adhesion in a manner akin to E. coli. Furthermore, other infectious bacteria, such as Salmonella sp. and Pseudomonas $\mathrm{sp}$. have been shown to have zeta potentials of $-16.6 \mathrm{mV}$ and $-46.9 \mathrm{mV}$ respectively ${ }^{53}$, indicative of high polar surface free energy components, thus, their adhesion is likely to be counteracted by high polar surface free energy surfaces. This suggests that the adhesion of a good range of harmful prokaryotic cells can be counteracted on highly polar surfaces, making SFE analysis an interesting strategy for selectively preventing bacterial adhesion on materials.

\section{Conclusion}

In this study, we have used $S$. cerevisiae and E. coli as model eukaryotic and prokaryotic cells to monitor, in real time, several aspects of cell adhesion that are important for understanding the underlying adhesion mechanisms. To achieve this, we employed two materials, gold and silica (native, and silanized), to unravel the effect of surface free energy on cell adhesion 
kinetics under flow and the adhesion behavior in stagnant liquid, including their time-dependent cytoskeletal changes. For comparison with a human eukaryotic cell line, we performed reference experiments on HEK cells.

The results show that, while $S$. cerevisiae adhesion is faster and displays positive cooperativity, E. coli adhesion is much slower and less cooperative. The adhesion rate for both cells increases with surface hydrophobicity, thus, revealing that hydrophobic forces drive the adhesion kinetics.

In the absence of flow, we show that within the time scale of hours, $S$. cerevisiae display higher adhesion on silica compared to gold. On the other hand, E. coli shows the opposite behavior, displaying higher adhesion on gold than silica. Remarkably, we found that $S$. cerevisiae detach on all surfaces, while $E$. coli detach on both the modified on unmodified silica, with little or no detachment on gold. For both cell types, in the long term, up to days, the highest levels of cell detachment were measured on silica and lowest on gold. From a SFE analysis, we conclude that the adhesion of both cells with, and without flow is strongly modulated by surface free energy: Generally, a high SFE surface promotes yeast adhesion and hinders $E$. coli adhesion. Specifically, the adhesion levels and long-term cell retention are determined by the balance between the polar and dispersive surface free energy components. A high polar SFE surface, such as silica enhance $S$. cerevisiae adhesion but impede $E$. coli adhesion, while a high dispersive SFE surface (e.g., gold) enhance long term cell retention for both cell types.

In addition, we have explored, not only the surface free energy dependence of the adhesion and detachment of $S$. cerevisiae and E. coli, but also the viscoelastic changes associated with their different adhesion phases. Our analysis shows that cell-specific adhesion phases are linked to distinct viscoelastic states. Therefore, viscoelastic signatures highlight the adhesion mechanisms of each cell type, thus distinguish the adhesion mechanisms of yeast and 
E. coli. In addition, we show that for both cell types, viscoelasticity is related to surface free energy: Cells are stiffer on low surface free energy surfaces, which suggests that cells alter their cytoskeletal organization in response to changes in SFE, and this may explain the association between cell adhesion and SFE.

Finally, we show that the surface free energy dependence of HEK cell adhesion is comparable to that of yeast: The adhesion of both cells increases with surface free energy with the polar component playing a major role. Therefore, in terms of application, the results indicate that biomaterial surfaces for medical implants can be intelligently engineered to enhance the adhesion of a desired eukaryotic cell type, while inhibiting the adhesion of a wide variety of infectious bacteria by tuning the surface free energy of the material. For instance, for applications for which eukaryotic cell adhesion is desired, material selection and/or surface modification should aim at high SFE surfaces with a high polar contribution. Since cells differ in surface properties, similar studies involving other cell types would be beneficial. Another important application relates to biosensors and cell sorting, which usually require the selective binding of target cells to receptor layers. Our results suggest that such surfaces can be tuned from a surface energy point of view to enhance the binding of target cells, thus, improving selectivity and detection limits.

\section{Acknowledgement}

This work was financed by the KU Leuven project C14/15/066 "Smart Cellular Scaffolds" and the Research Foundation Flanders FWO, project G.0791.16N "Utilizing interfacial impedanceand heat-transfer phenomena in advanced monitoring- and switching devices". The authors would like to thank Prof. Dr. Liesbet Lagae and Tim Steylaerts (both in IMEC, Belgium) for providing access to the QCM-D instrument. Also, we greatly appreciate Prof. Dr. Kevin 
Verstrepen (KU Leuven and Flemish Institute of Biotechnology VIB) for stimulating discussions.

\section{References}

1 Adams, J. C.; Watt, F. M. Regulation of Development and Differentiation by the Extracellular Matrix. Development. 1993, 117, 1183-1198.

2 Huang, S.; Ingber, D. E. The Structural and Mechanical Complexity of Cell-Growth Control. Nat. Cell Biol. 1999, 1, e131.

3 Lauffenburger, D. A.; Horwitz, A. F. Cell Migration: A Physically Integrated Molecular Process. Cell. 1996, 84, 359-369.

4 Christ, K. V.; Turner, K. T. Methods to Measure the Strength of Cell Adhesion to Substrates. J. Adhes. Sci. Technol. 2010, 24, 2027-2058.

5 Zhang, S.; Bai, H.; Yang, P. Real-Time Monitoring of Mechanical Changes During Dynamic Adhesion of Erythrocytes to Endothelial Cells by QCM-D. Chem. Commun. 2015, 51, 11449-11451.

6 Khalili, A.; Ahmad, M. A Review of Cell Adhesion Studies for Biomedical and Biological Applications. Int. J. Mol. Sci. 2015, 16, 18149-18184.

7 Nandakumar, A.; Barradas, A.; de Boer, J.; Moroni, L.; van Blitterswijk, C.; Habibovic, P. Combining Technologies to Create Bioactive Hybrid Scaffolds for Bone Tissue Engineering. Biomatter. 2013, 3, e23705.

8 Watarai, E.; Matsuno, R.; Konno, T.; Ishihara, K.; Takai, M. QCM-D Analysis of Material-Cell Interactions Targeting a Single Cell During Initial Cell Attachment. Sens. Actuator B-Chem. 2012, 171, 1297-1302.

9 Kwon, K. W.; Choi, S. S.; Lee, S. H.; Kim, B.; Lee, S. N.; Park, M. C.; Kim, P.; Hwang, S. Y.; Suh, K. Y. Label-Free, Microfluidic Separation and Enrichment of Human Breast Cancer Cells by Adhesion Difference. Lab Chip. 2007, 7, 1461-1468.

10 Stamp, M.; Jötten, A.; Kudella, P.; Breyer, D.; Strobl, F.; Geislinger, T.; Wixforth, A.; Westerhausen, C. Exploring the Limits of Cell Adhesion Under Shear Stress Within Physiological Conditions and Beyond on a Chip. Diagnostics. 2016, 6, 38.

11 Wang, Y. K.; Chen, C. S. Cell Adhesion and Mechanical Stimulation in The Regulation of Mesenchymal Stem Cell Differentiation. J. Cell. Mol. Med. 2013, 17, 823-832.

12 Garrett, T. R.; Bhakoo, M., Zhang, Z. Bacterial Adhesion and Biofilms on Surfaces. Prog. Nat. Sci. 2008, 18, 1049-1056. 
13 Groll, J.; Fiedler, J.; Bruellhoff, K.; Moeller, M.; Brenner, R. E. Novel Surface Coatings Modulating Eukaryotic Cell Adhesion and Preventing Implant Infection. Int. J. Artif. Organs. 2009, 32, 655-662.

14 Gallo, J.; Holinka, M.; Moucha, C. Antibacterial Surface Treatment for Orthopaedic Implants. Int. J. Mol. Sci. 2014, 15, 13849-13880.

15 Verstrepen, K. J.; Klis, F. M. Flocculation, Adhesion and Biofilm Formation in Yeasts. Mol. Microbiol. 2006, 60, 5-15.

16 Chen, J. Y.; Shahid, A.; Garcia, M. P.; Penn, L. S.; Xi, J. Dissipation Monitoring for Assessing EGF-Induced Changes of Cell Adhesion. Biosens. Bioelectron. 2012, 38, 375-381.

17 Felding-Habermann, B.; Habermann, R.; Saldívar, E.; Ruggeri, Z. M. Role of 3 Integrins in Melanoma Cell Adhesion to Activated Platelets Under Flow. $J$. Biol. Chem. 1996, 271, 5892-5900.

18 Teodósio, J. S.; Simões, M.; Melo, L. F.; Mergulhão, F. J. Flow Cell Hydrodynamics and Their Effects on E. coli Biofilm Formation under Different Nutrient Conditions and Turbulent Flow. Biofouling. 2011, 27, 1-11.

19 Ungai-Salánki, R.; Peter, B.; Gerecsei, T.; Orgovan, N.; Horvath, R.; Szabó, B. A Practical Review on The Measurement Tools for Cellular Adhesion Force. Adv. Colloid Interface Sci. 2019, 269, 309-333.

20 Puech, P. H.; Taubenberger, A.; Ulrich, F.; Krieg, M.; Muller, D. J.; Heisenberg, C. P. Measuring Cell Adhesion Forces of Primary Gastrulating Cells from Zebrafish Using Atomic Force Microscopy. J. Cell Sci. 2005, 118, 4199-4206.

21 Wang, N.; Butler, J. P.; Ingber, D. E. Mechanotransduction Across the Cell Surface and Through the Cytoskeleton. Science. 1993, 260, 1124-1127.

22 Birkbeck, A. L.; Flynn, R. A.; Ozkan, M.; Song, D.; Gross, M.; Esener, S. C. VCSEL Arrays as Micromanipulators in Chip-Based Biosystems. Biomed. Microdevices. 2003, $5,47-54$.

23 Rosenthal, A.; Voldman, J. Dielectrophoretic Traps for Single-Particle Patterning. Biophys. J. 2005, 88, 2193-2205.

24 Betlem, K.; Hoksbergen, S.; Mansouri, N.; Down, M.; Losada-Pérez, P.; Eersels, K.; Van Grinsven, B.; Cleij, T. J.; Kelly, P.; Sawtell, D.; Zubko, M.; Banks, C.; Peeters, M. Real-Time Analysis of Microbial Growth by Means of the Heat-Transfer Method (HTM) Using Saccharomyces cerevisiae as Model Organism. Physics in Medicine. 2018, 6, 1-8.

25 Cornelis, P.; Givanoudi, S.; Yongabi, D.; Iken, H.; Duwé, S.; Deschaume, O.; Robbens, J.; Dedecker, P.; Bartic, C.; Wübbenhorst, M.; Schöning, M. J.; Heyndrickx, M.; Wagner. P. Sensitive and Specific Detection of E. coli Using Biomimetic Receptors in 
Combination with a Modified Heat-Transfer Method. Biosens. Bioelectron. 2019, 136, 97-105.

26 Eersels, K.; van Grinsven, B.; Ethirajan, A.; Timmermans, S.; Jiménez Monroy, K. L; Bogie, J. F.; Punniyakoti, S.; Vandenryt, T.; Hendriks, J. J.; Cleij, T. J.; Daemen, M. J.; Somers, V.; De Ceuninck, V.; Wagner, P. Selective Identification of Macrophages and Cancer Cells Based on Thermal Transport Through Surface-Imprinted Polymer Layers. ACS Appl. Mater. Interfaces. 2013, 5, 7258-7267.

27 Alexander, T. E.; Lozeau, L. D.; Camesano, T. A. QCM-D Characterization of TimeDependence of Bacterial Adhesion. Cell Surf. 2019, 100024.

28 Khorshid, M.; Losada-Pérez, P.; Wackers, G.; Yongabi, D.; Renner, F. U.; Thoelen, R.; Wagner, P. Real-Time Monitoring of Interactions Between Ebola Fusion Peptide and Solid-Supported Phospholipid Membranes: Effect of Peptide Concentration and Layer Geometry. Physics in Medicine. 2017, 4, 1-7.

29 Rodahl, M.; Kasemo, B. A Simple Setup to Simultaneously Measure the Resonant Frequency and the Absolute Dissipation Factor of a Quartz Crystal Microbalance. Rev. Sci. Instrum. 1996, 67, 3238-3241.

30 Fredriksson, C.; Kihlman, S.; Rodahl, M.; Kasemo, B. The Piezoelectric Quartz Crystal Mass and Dissipation Sensor: a Means of Studying Cell Adhesion. Langmuir. 1998, 14, 248-251.

31 Chen, J. Y.; Penn, L. S.; Xi, J. Quartz Crystal Microbalance: Sensing Cell-Substrate Adhesion and Beyond. Biosens. Bioelectron. 2018, 99, 593-602.

32 Saitakis, M.; Gizeli, E. Acoustic Sensors as a Biophysical Tool for Probing Cell Attachment and Cell/Surface Interactions. Cell. Mol. Life Sci. 2012, 69, 357-371.

33 Westas, E.; Svanborg, L. M.; Wallin, P.; Bauer, B.; Ericson, M. B.; Wennerberg, A.; Mustafa, K.; Andersson, M. Using QCM-D to Study the Adhesion of Human Gingival Fibroblasts on Implant Surfaces. J. Biomed. Mater Res. B. 2015, 103, 3139-3147.

34 Zhou, T.; Marx, K. A.; Dewilde, A. H.; McIntosh, D.; Braunhut, S. J. Dynamic Cell Adhesion and Viscoelastic Signatures Distinguish Normal from Malignant Human Mammary Cells Using Quartz Crystal Microbalance. Anal. Biochem. 2012, 421, 164171.

35 Harnett, E. M.; Alderman, J.; Wood, T. The Surface Energy of Various Biomaterials Coated with Adhesion Molecules Used in Cell Culture. Colloids Surf. B. 2007, 55, 9097.

36 Nakamura, M.; Hori, N.; Ando, H.; Namba, S.; Toyama, T.; Nishimiya, N.; Yamashita, K. Surface Free Energy Predominates in Cell Adhesion to Hydroxyapatite Through Wettability Mater. Sci. Eng. C. 2016, 62, 283-292.

37 Owens, D. K.; Wendt, R. C. Estimation of the Surface Free Energy of Polymers. $J$. Appl. Polym. Sci. 1969, 13, 1741-1747. 
38 Gentleman, M. M.; Gentleman, E. The Role of Surface Free Energy in OsteoblastBiomaterial Interactions. Int. Mater. Rev. 2014, 59, 417-429.

39 do Nascimento, R. M.; Sarig, U.; da Cruz, N. C.; de Carvalho, V. R.; Eyssartier, C.; Siad, L.; Ganghoffer, J. F.; Hernandes, A. C.; Rahouadj, R. Optimized-Surface Wettability: A New Experimental 3D Modeling Approach Predicting Favorable Biomaterial-Cell Interactions Adv. Theory Simul. 2019, 2, 1900079.

40 Mediaswanti, K.; Wen, C.; Ivanova, E. P.; Berndt, C. C.; Pham, V. T.; Malherbe, F.; Wang, J. Investigation of Bacterial Attachment on Hydroxyapatite-Coated Titanium and Tantalum. Int. J. Surf. Sci. Eng. 2014, 15, 8, 255-263.

41 Saini, M.; Singh, Y.; Arora, P.; Arora, V.; Jain, K. Implant Biomaterials: A Comprehensive Review. World J. Clin. Cases. 2015, 3, 52.

42 Brandon, H. J.; Young, V. L.; Jerina, K. L.; Wolf, C. J. Analysis of Explanted Silicone/Silica Composite Breast Implants. Adv. Compos. Lett. 2000, 9, 115-123.

43 Ballarre, J.; Ceré, S. M. Bioactive Silica-Based Coating on Stainless Steel Implants, in: Klein, L., Aparicio, M., Jitianu, A. (Eds.), Handbook of Sol-Gel Science and Technology: Processing, Characterization and Applications. Springer, Berlin. 2018, pp. 3505-3553.

44 Jun, S. H.; Lee, E. J.; Yook, S. W.; Kim, H. E.; Kim, H. W.; Koh, Y. H. A Bioactive Coating of a Silica Xerogel/Chitosan Hybrid on Titanium by a Room Temperature SolGel Process. Acta Biomater. 2010, 6, 302-307.

45 Botstein, D.; Fink, G. R. Yeast: An Experimental Organism for 21st Century Biology. Genetics. 2011, 189, 695-704.

46 Friedlander, R. S.; Vogel, N.; Aizenberg, J. Role of Flagella in Adhesion of Escherichia coli to Abiotic Surfaces. Langmuir. 2015, 31, 6137-6144.

47 Imlay, J. A. The Molecular Mechanisms and Physiological Consequences of Oxidative Stress: Lessons from A Model Bacterium. Nat. Rev. Microbiol. 2013, 11, 443-454.

48 Idalia, V. M. N.; Bernardo, F. Escherichia coli as a Model Organism and Its Application in Biotechnology, in: Amidou Samie, A. (Ed.), Escherichia coli - Recent Advances on Physiology, Pathogenesis and Biotechnological Applications. IntechOpen. Rijeka, 2017, 253-274.

49 Żenkiewicz, M. Methods for the Calculation of Surface Free Energy of Solids. J. Achiev. Mater. Manuf. Eng. 2007, 24, 137-145.

$50 \quad$ Yongabi, D.; Khorshid, M.; Losada-Pérez, P.; Eersels, K.; Deschaume, O.; D'Haen, J.; Bartic, C.; Hooyberghs, J.; Thoelen, R.; Wübbenhorst, M.; Wagner, P. Cell Detection by Surface Imprinted Polymers SIPs: A Study to Unravel the Recognition Mechanisms. Sens. Actuator B-Chem. 2018, 255. 907-917. 
51 Nečas, D.; Klapetek, P. Gwyddion: An Open-Source Software for SPM Data Analysis. Open Phys. 2012, 10, 181-188.

52 Robilliard, L.; Kho, D.; Johnson, R.; Anchan, A.; O’Carroll, S.; Graham, E. The Importance of Multifrequency Impedance Sensing of Endothelial Barrier Formation Using ECIS Technology for the Generation of a Strong and Durable Paracellular Barrier. Biosensors. 2018, 8, 64.

53 Soni, K. A.; Balasubramanian, A. K.; Beskok, A.; Pillai, S. D. Zeta Potential of Selected Bacteria in Drinking Water When Dead, Starved, or Exposed to Minimal and Rich Culture Media. Curr. Microbiol. 2008, 56, 93-97.

54 Vandrangi, P.; Jreij, P.; Rajapaksa, T.E.; Bansal, N.; Lo, D.D.; Rodgers, V. G. J. Novel in situ normal streaming potential device for characterizing electrostatic properties of confluent cells. Review of Scientific Instruments. 2012, 83, 074302.

55 Sharma, P. K.; Rao, K. H. Adhesion of Paenibacillus polymyxa on Chalcopyrite and Pyrite: Surface Thermodynamics and Extended DLVO Theory. Colloids Surf. B. 2003, 29, 21-38.

56 Kang, S.; Choi, H. Effect of Surface Hydrophobicity on the Adhesion of S. cerevisiae onto Modified Surfaces by Poly (Styrene-ran-sulfonic Acid) Random Copolymers. Colloids Surf. B. 2005, 46, 70-77.

57 Marx, K. A.; Zhou, T.; Warren, M.; Braunhut, S. J. Quartz Crystal Microbalance Study of Endothelial Cell Number Dependent Differences in Initial Adhesion and Steady-State Behavior: Evidence for Cell-Cell Cooperativity in Initial Adhesion and Spreading. Biotechnol. Prog. 2003, 19, 987-999.

58 Whitty, A. Cooperativity and Biological Complexity. Nat. Chem. Biol. 2008, 4, 435439

59 Larsen, M.; Artym, V. V.; Green, J. A.; Yamada, K. M. The Matrix Reorganized: Extracellular Matrix Remodelling and Integrin Signalling. Curr. Opin. Cell Biol. 2006, $18,463-471$.

60 Lord, M. S.; Modin, C.; Foss, M.; Duch, M.; Simmons, A.; Pedersen, F. S.; Milthorpe, B. K.; Besenbacher, F. Monitoring Cell Adhesion on Tantalum and Oxidised Polystyrene Using a Quartz Crystal Microbalance with Dissipation. Biomaterials. 2006, 27, 4529-4537.

61 Cuvelier, D.; Théry, M.; Chu, Y.S.; Dufour, S.; Thiéry, J.P.; Bornens, M.; Nassoy, P.; Mahadevan, L. The Universal Dynamics of Cell Spreading. Curr. Biol. 2007, 17, 694699.

62 Tareste, D.; Pincet, F.; Lebeau, L.; Perez, E. Hydrophobic Forces and Hydrogen Bonds in the Adhesion between Retinoid-coated Surfaces. Langmuir. 2007, 23, 3225-3229.

63 Israelachvili, J.; Pashley, R. The Hydrophobic Interaction is Long Range, Decaying Exponentially with Distance. Nature. 1982, 300, 341. 
64 Hermansson, M. The DLVO Theory in Microbial Adhesion. Colloids Surf. B. 1999, 14, 105-119.

65 Farahat, M.; Hirajima, T.; Sasaki, K.; Doi, K. Adhesion of Escherichia coli onto Quartz, Hematite and Corundum: Extended DLVO Theory and Flotation Behavior. Colloids Surf. B. 2009, 74, 140-149.

66 Busscher, H. J.; Norde, W.; Sharma, P. K.; van der Mei, H. C. Interfacial ReArrangement in Initial Microbial Adhesion to Surfaces. Curr. Opin. Colloid. Interface. Sci. 2010, 15, 510-517.

67 Lerebour, G.; Cupferman, S.; Bellon-Fontaine, M.N. Adhesion of Staphylococcus aureus and Staphylococcus epidermidis to the Episkin ${ }^{\circledR}$ Reconstructed Epidermis Model and to an inert 304 Stainless Steel Substrate. J. Appl. Microbiol. 2004, 97, 7-16.

68 Kłodzińska, E.; Szumski, M.; Hrynkiewicz, K.; Dziubakiewicz, E.; Jackowski, M.; Buszewski, B. Differentiation of Staphylococcus aureus Strains by CE, Zeta Potential and Coagulase Gene Polymorphism. Electrophoresis 2009, 30, 3086-3091.

69 Gerson, D.F.; Scheer, D. Cell Surface Energy, Contact Angles and Phase Partition III. Adhesion of Bacterial Cells to Hydrophobic Surfaces. BBA-Biomembranes 1980, 602, 506-510.
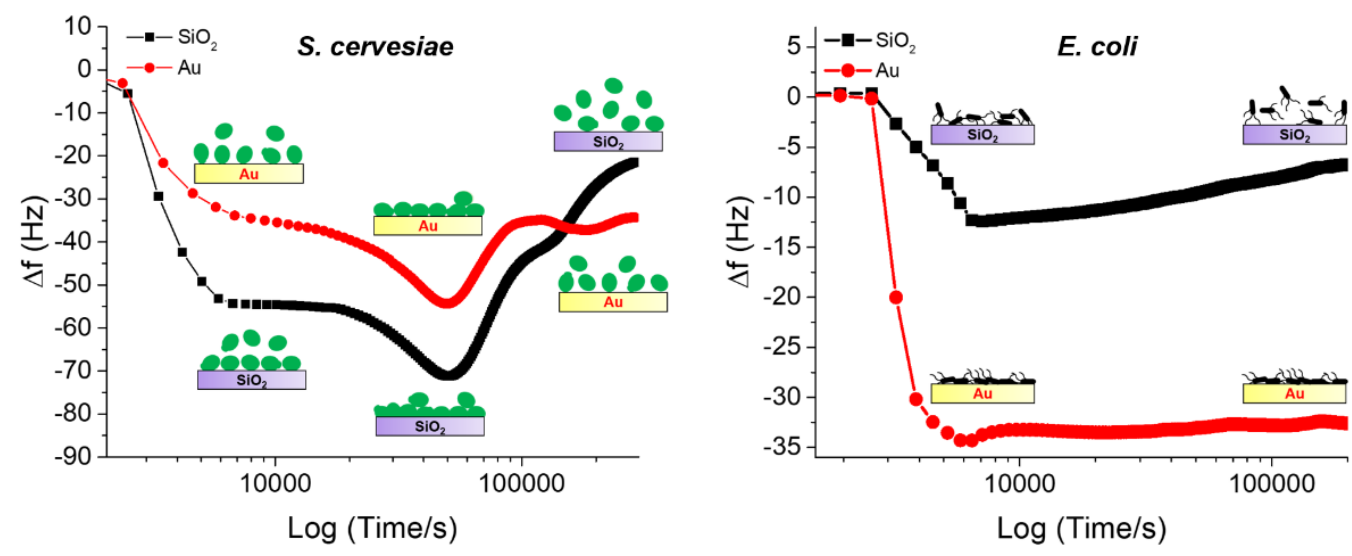